\title{
Landscapes drive the dispersal of Monochamus alternatus, vector of the pinewood nematode, revealed by Whole-genome resequencing
}

\author{
yechen $\mathrm{Li}^{1}$, Wanlong Huang ${ }^{2}$, Xiaohong $\mathrm{Han}^{1}$, Xiaoqian Weng ${ }^{1}$, Rebeca \\ Carballar-Lejarazú ${ }^{3}$, Rong Wang ${ }^{1}$, Xia Hu${ }^{1}$, Guanghong Liang ${ }^{1}$, Shiguo Huang ${ }^{1}$, Chunlan \\ Lian $^{4}$, Songqing $\mathrm{Wu}^{1}$, and Feiping Zhang $^{1}$ \\ ${ }^{1}$ Fujian Agriculture and Forestry University \\ ${ }^{2}$ Novogene Bioinformatics Institute \\ ${ }^{3}$ University of California Irvine Department of Microbiology and Molecular Genetics \\ ${ }^{4}$ Asian Natural Environmental Science Center
}

July 30, 2020

\begin{abstract}
Pine wilt disease (PWD), Bursaphelenchus xylophilus, is an extremely threatening invasion forest disease throughout the world, especially in Asia. B. xylophilus is spread in Asia by vector beetles of Monochamus alternatus, which has long no effective control method. Understanding of landscape effects on the dispersal and outbreaks of forest pests is crucial to establishing effective ecological control strategies. Here, we analyzed the samples of M. alternatus collected at landscapes in order to estimate the effects of landscape types on the genetic structure and dispersal of M. alternatus. The landscapes included the geographical scales, forest types and land uses. The individuals of M. alternatus were genotyped by using whole-genome resequencing. Population genetic structures were clearly differentiated at the intermediate scale, suggesting the intermediate scale is an effective barrier against natural dispersal of M. alternatus. We used the least-coat distances, least-cost transect analysis, and distance-based redundancy analysis to estimate the effects of forest types and land uses within the fine scales. The results showed that the gene flow and genetic diversity were positively correlated with host and mixed forests, whereas negatively with non-host forests. Among land-use landscapes, the roads had the positive effect on gene flow and genetic diversity but farmland and urban uses had negative effects. This highlights that human-mediated transport via roads was likely to be the main factor leading to the long-distance invasion of M. alternatus, whereas non-host landscapes could suppress the spread of this species. These findings may be useful to control the PWD dispersed by M. alternatus.
\end{abstract}

\section{KEYWORDS}

Monochamus alternatus, pine wilt disease, whole-genome resequencing, least-cost transect analysis, distancebased redundancy analysis, landscape types

\section{INTRODUCTION}

Biotic invaders are a major threat, causing great destruction to the environment, economies, and biological safety, and with the development of transportation and commerce under globalization, few, if any, areas have escaped these invasions (Mack et al., 2000; Sun, Yuan, \& Ou, 2002; Walker \& Steffen, 1996). Pine wilt disease (PWD) is a major disease that invades forests and is highly destructive to its host pines. The disease spreads quickly, causes disease over a wide range, and is difficult to control and cure; thereby, PWD is also known as the "cancer" of pines (Naves, Camacho, Sousa, \& Quartau, 2007; Wu et al., 2013). The disease, native to North America, was introduced into Japan in 1905, and then outbreaks occurred successively in 
China, South Korea, Mexico, Portugal, and Spain (Mota \& Vieira, 2008; Zhao, Mota, Vieira, Butcher, \& Sun, 2013). To date, PWD has caused serious negative effects on the economy and the environment of many countries. From 2001 to 2012, the European Union spent thirty million euros on the surveillance and control of the disease, with projected losses of up to twenty billion euros in Europe by 2030 (Soliman et al., 2012). In Japan, at least $700,000 \mathrm{~m}^{3}$ of pine trees are lost every year (Mamiya \& Shoji, 2009). In China, the direct and indirect economic losses due to PWD have reached 100 billion yuan, and the area of Pinus massoniana, its main host, decreased by 8.07 million ha from 1994 to 2013, with 60 million ha of pine forests that remain greatly threatened by this disease (Ye, 2019). In addition, according to the hypothesis of an insect-fungus complex (Lu, Wingfield, Gillette, \& Sun, 2011), the native ecosystems are at risk of reinvasion because pine wilt disease acquired greater adaptability in the invasion of new habitats (Maehara \& Futai, 1997; Zhao et al., 2013).

The causal agent of PWD is the pinewood nematode (PWN,Bursaphelenchus xylophilus), which is spread by vector beetles of the genus Monochamus (Mota \& Vieira, 2008). The main vector beetles in North America include M. carolinensis, M. scutellatus, and M. mutator (Akbulut \& Stamps, 2011). M. galloprovincialis is the only insect vector in Portugal and other European countries (Sousa et al., 2001); whereas in several Asian countries, including China, the main vector is $M$. alternatus. Therefore, the effective control of $M$. alternatus plays an important role in controlling the continued spread of PWD in Asia (Zhao et al., 2008). In addition to self-migration, human-mediated and environmental factors are also important in the spread of $M$. alternatus . Moreover, because of the host dominance and ecosystem dominance of forest pests (Lian \& Zhang, 2005), it is necessary to better understand the influence of host and nonhost landscapes on the dispersal behavior of this species.

The landscape plays an important role in the ecological processes (Turner, 1989). Landscape diversity can have major effects on the dispersal of forest pests (Thibaud et al., 2014; Foley et al., 2005), by either promoting or inhibiting the gene flow of dispersing insects and their movement between different landscape types (Fontaine, Bergerot, Le Viol, \& Julliard, 2016; Yadav, Stow, \& Dudaniec, 2019). The abundance of insects generally increases with the density of host plants, and insects have a tendency to migrate to patches of host plants (Underwood, Inouye, \& Hambäck, 2014). The evidence is also increasing that with high tree diversity associational resistance can form against pests and reduce their damage (Damien et al., 2016; Harri, Koricheva, \& Kai, 2007; Jactel, Goulard, Menassieu, \& Goujon, 2002; Jactel \& Brockerhoff, 2007; Jacte et al., 2015). Especially in mixed stands with hosts and nonhosts, the nonhosts can reduce the proportion of hosts available to the pest, and the natural enemies of pests are also typically more abundant, both of which increase the resistance to forest pests (Barbosa et al., 2009; Quayle, Regniere, Cappuccino, \& Dupont, 2003). In addition to the effects of tree species in the landscape, other landscape types (e.g., urban areas, farmlands, and roads) can also have different effects on the gene flow and dispersal of insects (Keller, Strien, \& Holderegger, 2012; Ortego, Bonal, \& Muñoz, 2010; Yadav et al., 2019). Therefore, in a heterogeneous landscape, it is particularly important to understand the relationships between landscape types and pest dispersal behavior, population genetic structure, and gene flow. With such an understanding, the mechanisms to explain pest occurrence can be revealed, and scientific and effective ecological control methods can be established.

Although the relationship between landscape and some longhorn beetles has been described, most studies used microsatellite or mitochondrial DNA markers to study the invasion history and the influence of environmental factors such as climate and altitude (David, Giffard, Piou, Roques, \& Jactel, 2016; Haran, Roques, Barnard, Robinet, \& Roux, 2015; Haran et al., 2017; Javal et al., 2017; Javal et al., 2019; Koutroumpa, Rougon, Bertheau, Lieutier, \& Roux, 2013; Tsykun et al., 2019). However, because of the limited number of polymorphic sites and the lack of detailed information on tree species, the dispersal behavior and the genetic model of $M$. alternatus at a fine scale has not been studied. In particular, a comprehensive description of the relationships between this species and finely classified tree species and nonhost landscapes such as urban areas, farmlands, and roads is lacking. This information is particularly important to clarify the dispersal behavior of M. alternatus in a heterogeneous landscape, as well as to efficiently manage and control PWD. With the emergence of next-generation sequencing, millions of single nucleotide polymorphisms (SNPs) can 
be detected and compared with microsatellite markers. In addition, fewer samples are needed to obtain more accurate and better information on population structure. Thus, next-generation sequencing not only facilitates the development of landscape genetics but also is expected to become the standard in environmental association analysis in coming years (Rellstab et al., 2015; Jeffries et al., 2016). Currently, SNP analysis is becoming more widely accepted and applied in landscape research (Bay et al., 2018; Nancy et al., 2020; Zhen et al., 2017). Moreover, with the large numbers of SNPs, the analysis is more powerful, and the differences between populations can be detected at a fine scale (Liu et al., 2019; Rašić, Filipović, Weeks, \& Hoffmann, 2014).

In this study, the whole genome of $M$. alternatus was resequenced at different landscape scales (intermediate and fine scales), and the tree species in the forested landscape were classified in detail based on a forest inventory of China. To analyze the influence of multiple scales, first, the population structure at intermediate and fine scales was compared, and then, the relations between gene flow and genetic diversity and forests with different tree species, urban areas, farmlands, roads, and water sources were studied at a fine scale. At the fine scale, the isolation-by-distance (IBD) and the least-cost distance (LCP) models(Adriaensen et al., 2003) were used, and the distances calculated by the models were correlated with genetic distance. To define the resistance surface more objectively and further study the effects of different landscape types on gene flow and dispersal of $M$. alternatus, the least-cost transect analysis (LCTA) developed by Strien, Keller, \& Holderegger. (2012) and maximum-likelihood population effects (MLPE) developed by Clarke, Rothery, \& Raybould. (2002) were adopted. The distance-based redundancy analysis (db-RDA) (Legendre \& Anderson, 1999) and the generalized additive model (GAM) (Lengyel \& Podani, 2015) were also used to test the influence of the landscape composition around each sample point on genetic diversity.

\section{MATERIALS AND METHODS}

\subsection{Study area and sampling}

M. alternatus is the main vector of PWN in Asia and is especially widely distributed in southern China. This study was mainly conducted in Shunchang (26 39' to $27 \mathrm{deg} 121^{\prime} \mathrm{N}, 117 \mathrm{deg} 29^{\prime}$ to $\left.118 \mathrm{deg} 14^{\prime} \mathrm{E}\right)$ and Xiapu (26deg25' to $27 \operatorname{deg} 16$ 'N , 119deg46' to 120deg28'E) in Fujian Province of southern China, with a geographical distance of approximately $250 \mathrm{~km}$ separating the two areas. Both sites have a subtropical monsoon climate. In Shunchang, the average annual temperature is $18.5 \mathrm{degC}$, and the average annual rainfall is $1,756 \mathrm{~mm}$. In Xiapu, the average annual temperature is $18.8 \mathrm{deg} \mathrm{C}$, and the average annual rainfall is $1,800 \mathrm{~mm}$.

P. massoniana and P. elliottii are natural hosts of $M$. alternatus, and they are widely distributed in the two areas. Moreover, urban areas, farmlands, roads, and water sources are embedded in the forested landscape. The landscape types were divided into ten categories: P. massoniana, C. lanceolata, P. elliottii, mixed forest (including some hosts), broad-leaved forest, urban, farmland, road, water, and nudation (Figure 1). Samples were collected when adults are active from May to October in 2018 from 22 sites (12 sites in Shunchang (SC) and 10 sites in Xiapu (XP); Figure 1; Table 1) using a trapping method. The sample size ranged from seven to fourteen individuals per site (mean $=9.77+-1.93(\mathrm{SE})$; Table 1$)$. The maximum geographic distance between fine-scale sampling points was $10 \mathrm{~km}$ and a the minimum of was $400 \mathrm{~m}$. All adult beetles were perserved in absolute ethanol and stored at -80 degC. A total of 215 adults M.alternatus were collected (115 in SC and 100 in XP).

\subsection{DNA extraction, library preparation, and sequencing}

Total genomic DNA was extracted from mesothorax muscle tissues of each beetle for library preparation and sequencing using the TruSeq DNA Sample Preparation kit (Illumina, USA)according to the manufacturer's instructions. Sequencing libraries were generated using the Truseq Nano DNA HT Sample Preparation kit (Illumina, USA) following the manufacturer's recommendations, and index codes were added to label sequences from each sample. For each individual, the DNA sample was sheared into fragments of $350 \mathrm{bp}$ fragments by using a Covaris S2 (Covaris). The DNA fragments were end-polished, A-tailed, and ligated 
with a full-length adapter for Illumina sequencing with further PCR amplification. The PCR products were purified (AMPure XP system), and the libraries were analyzed for size distribution using an Agilent 2100 Bioanalyzer and quantified using real-time PCR. The DNA fragments were then processed and sequenced using the Illumina HiSeq PE150 platform. Quality control was achieved by removing low costs and lowquality paired reads (reads with [?]10\% unidentified nucleotides; $>10$ nt aligned to the adaptor, allowing $[?] 10 \%$ mismatches; $>50 \%$ of bases having phred quality $<5$; and putative PCR duplicates generated in the library construction process), which mainly resulted from base-calling duplicates and adaptor contamination.

\subsection{Reads mapping and SNP calling}

Raw sequence reads were mapped to the $M$. alternatus reference genome using the Burrows-Wheeler Aligner (BWA) with the command 'mem -t 4 -k $32-\mathrm{M}$ ' (Li \& Durbin, 2009). To reduce mismatches generated by PCR amplification before sequencing, duplicated reads were removed with SAMtools (Li et al., 2009). After alignment, SNP calling was performed on a population scale using a Bayesian approach as implemented in the package SAMtools, and then genotype likelihoods from reads for each individual at each genomic location and the allele frequencies in the sample were calculated with a Bayesian approach. The 'mpileup' command was used to identify SNPs with the parameters as '-q 1 -C 50 -t SP -t DP -m 2 -F 0.002'. Specifically, a SNP was retained when it met the following criteria: coverage depth [?]2 and [?]30, minor allele frequency (MAF) [?]0.05, MISS [?]0.1.

\subsection{Population genetics analyses}

Within-population diversity was assessed by expected heterozygosity $\left(\mathrm{H}_{\mathrm{E}}\right)$, average self-coancestry $(\mathrm{s})$, fixation index $\left(\mathrm{F}_{\mathrm{IS}}\right)$, allelic diversity $(\mathrm{A})$, and mean number of alleles per locus $(\mathrm{K})$ using Metapop2 (LopezCortegano, Perez-Figueroa, \& Caballero, 2019). To analyze the population structure at the intermediate scale, a phylogenetic tree between Shunchang and Xiapu was constructed through 100 calculations of bootstrap values based on the neighbor-joining method and a principal component analysis was conducted, using MEGA 7.0 and genome-wide complex trait analysis (GCTA), respectively (Sudhir, Glen, \& Koichiro, 2016; Yang, Lee, Goddard, \& Visscher, 2011). ADMIXTURE version 1.3.0 (Alexander, Novembre, \& Lange, 2009) was used to analyze population genetic structure at the two scales. The $\mathrm{k}$ genetic clusters were tested, with $\mathrm{k}$ ranging from one to seven, and the best $\mathrm{k}$ was determined according to the smallest cross-validation $(\mathrm{CV})$ error. The vcftools (Auton \& Marcketta, 2015) was used to calculate the $\mathrm{F}_{\mathrm{ST}}$ between all pairs of sampled populations by averaging the values less than 0 after 5,000 bp windows and filtering (Supporting information Table S3, S4).

\subsection{Influence of landscape on gene flow and genetic distance}

To preliminarily predict the influence of the different landscape types on the genetic differentiation of $M$. alternatus, the distance models IBD and LCP were used at the fine scale (with Shunchang as an example). In the LCP model, four groups of resistance values were set for the ten landscape types base on the opinion method (Supporting information Table S5): $i$ ) host landscapes and roads were given the lowest resistance value (the resistance value of $P$. massoniana, $P$. elliottii, mixed-forest with hosts, and roads was 1 ), and nonhost landscapes (except roads) were divided into medium and high resistance (the medium resistance value of broad-leaved forest, $C$. lanceolata, water, and nudation was 8; the high resistance value of farmland was 64 and for urban was 512); ii ) host landscapes and roads were given the medium resistance value of 8 , whereas nonhost landscapes (except roads) were given the lowest resistance value of $1 ;$ iii ) host landscapes and roads were given the medium resistance value of 64 , whereas nonhost landscapes (except roads) were given the lowest resistance value of 1 ; iiii ) host landscapes and roads were given the high resistance value of 512, whereas nonhost landscapes (except roads) were given the lowest resistance value of 1 . The LCP on the four resistance surfaces was calculated using the R package gdistance (Vanetten, 2014). Finally, Mantel tests between the two distances and genetic distances $\left(\mathrm{F}_{\mathrm{ST}}\left(1-\mathrm{F}_{\mathrm{ST}}\right)\right)$ were performed in the $\mathrm{R}$ package ecodist (Goslee \& Urban, 2007).

In addition, to maintain objectivity, the least-cost transect analysis (LCTA) developed by Strien et al. (2012) was used to study the influence of landscape types on dispersal behavior and gene flow of M. alternatus at the 
fine scale. This analysis provided an effective solution to objectively define the resistance values of different landscape types based on transects. In the analysis, each landscape type in a linear path, with different transect widths, between two sampling points is quantified, and the correlation between those values and the genetic distance is analyzed. The analysis can also determine the probable migration habitats and the landscape types that either inhibit or facilitate the gene flow. However, it is unlikely that species will migrate directly between two points following a straight line. Therefore, the LCTA uses the least-cost path to replace the straight line between two points and then calculates the percentage of each landscape type in the transect. For each transect, the proportions of each of the landscape types and the transect length were used as explanatory variables.

In this study, the first step in the LCTA was to create a series of resistance surfaces, in which each landscape type (P. massoniana, C. lanceolata, P. elliottii , mixed forest (including some hosts), broad-leaved forest, urban, farmland, road, water, and nudation) was successively considered as the optimal dispersal habitat. The optimal dispersal habitat was given the lowest resistance value of 1 , whereas the other landscape types were given gradually increasing resistance values $\left(2^{3}, 2^{6}, 2^{9}\right)$ (Supporting information Table S6). A variety of transect widths $(200 \mathrm{~m}, 300 \mathrm{~m}, 600 \mathrm{~m})$ were evaluated. In each transect, Geospatial Modelling Environment v0.7.4.0 (Beyer, 2015) was used to calculate the proportions of each of the landscape types and the transect length. A total of $90 \mathrm{LCP}$ data sets were obtained (10 land cover types x 3 resistance values x 3 transect widths). The correlations between those variables (proportions of each of the landscape types and the transect length) and the $\mathrm{F}_{\mathrm{ST}}$ were tested through maximum-likelihood population effects (MLPE) (Clarke et al., 2002). In each MLPE, the model was estimated with restricted estimation maximum likelihood (REML), and the individual deme was used as a random effect. To explain the relationships between the different landscape types and the gene flow, Akaike's Information Criteria (AIC) (Gurka, 2006), which is considered to be effective in choosing an REML hybrid model, was used to select the optimal model from the 90 data sets.

\subsection{Influence of landscape on genetic diversity}

To reveal the influence of the composition of the landscape types around each sampling point on the genetic diversity, Arcgis10.2 (ESRI) was used to create circular buffers with radii of $300 \mathrm{~m}, 800 \mathrm{~m}$, and 1,000 m and with each sample point as the center. Then, the proportions of P. massoniana, C. lanceolata, P. elliottii , mixed forest (including some hosts), broad-leaved forest, urban, farmland, road, water, and nudation landscape types in each circular buffer were calculated. The db-RDA model (Legendre \& Anderson, 1999)was used to analyze whether the ten landscape types at the three scales could explain the genetic diversity. In addition, to explain the nonlinear relationship in the db-RDA analysis and explore whether those variables inhibited or facilitated the genetic diversity of M. alternatus, a flexible fitting method (GAM) (Lengyel \& Podani, 2015)was used to map the explanatory variables over the first two principal coordinates analysis (PCoA) axes.

\section{RESULTS}

\subsection{Whole-genome resequencing, mapping, and SNP detection}

The genome size was $836,201,995 \mathrm{bp}$, and individual genomes were sequenced to an average of $7 \mathrm{x}$ coverage, with the average coverage of $90 \%$ (Supporting information Table S1, S2). A total of 31,759,600 SNP markers were initially obtained from Shunchang, whereas 29,918,163 SNPs were obtained from Xiapu. After stringent filtering, 4,152,751 SNPs were identified from Shunchang and 3,298,993 from Xiapu. The filtered SNPs were used for subsequent analysis.

\subsection{Within-population diversity at a fine scale}

In Shunchang, the expected heterozygosity $\left(\mathrm{H}_{\mathrm{E}}\right)$ ranged from 0.2208 to 0.2383 , the average self-coancestry (s) ranged from 0.875 to 0.8799 , the allele richness (A) ranged from 0.7613 to 0.7752 , and the mean number of alleles per locus $(\mathrm{K})$ was close to 2 (Table 2). In Xiapu, the $\mathrm{H}_{\mathrm{E}}$ ranged from 0.2015 to 0.2127 , the $\mathrm{s}$ ranged from 0.8861 to 0.8895 , the A ranged from 0.7754 to 0.7674 , and the $\mathrm{K}$ was also close to 2 (Table 2 ). 
According to these five parameters, although the genetic diversity of populations at the fine scale was weak, there were certain differences.

\subsection{Population structure at different scales}

M. alternatus population structure was compared at intermediate and fine scales. As shown in the phylogenetic tree, the population in the two regions was divided into two branches at the intermediate scale (Figure 2A). Principal component analysis confirmed this result, having the populations from the two regions clearly separated (Figure 2B). ADMIXTURE was also used to analyze the population genetic structure between the two regions. In the ADMIXTURE figure (Figure 2C), each column represents an individual, with the length of the different colored segments representing the proportion of an ancestor in the individual genome. Because the CV error was the smallest at $\mathrm{K}=2(\mathrm{CV}$ error $=0.42066)$, the population genetic structure revealed two main differentiated gene pools (Figure 2C). Thus, the population in Shunchang was originated from one ancestor and the one from Xiapu was originated from a different ancestor, which is a conclusion consistent with the results of the phylogenetic tree and the PCA. In conclusion, the populations were clearly differentiated at the intermediate scale $(>250 \mathrm{~km})$, which clearly indicated the importance of geographic barriers against natural dispersal and gene flow of $M$. alternatus over long distances.

To reveal whether there were differences in population genetic structure at the fine scale, ADMIXTURE was also used to analyze the population genetic structures within Shunchang and Xiapu. According to the smallest CV error in Shunchang and Xiapu at $\mathrm{K}=2(\mathrm{CV}$ error $=0.49264$ and 0.47180 , respectively; Supporting information Figure S1), the populations at the fine scale formed two clusters. Thus, the populations in SC included two clusters, and those XP included two other clusters (Figure 3). Although the fine-scale genetic structure detected by ADMIXTURE was weak, with an increase in the $\mathrm{K}$ value, seven meaningful clusters were obtained (Supporting information Figure S2).

\subsection{Influence of landscape on gene flow and genetic distance}

According to the IBD model and the Mantel test in the Shunchang County, there was no significant $\left(\mathrm{r}\left(\mathrm{F}_{\mathrm{ST}}\right.\right.$, $\mathrm{IBD})=0.38, P=0.075$ ) (Figure 4A), but different landscape types had influence (Supporting information Figure S3). Among the four groups of resistance values, only the resistance surface created by the first group (the resistance value of $P$. massoniana, $P$. elliottii , mixed-forest with hosts, and road was 1; the medium resistance value of broad-leaved forest, $C$. lanceolata, water, and nudation was 8 ; the high resistance value of farmland was 64 and that of urban 512 ) (Figure $4 \mathrm{C}$ ) was significantly correlated $\left(\mathrm{r}\left(\mathrm{F}_{\mathrm{ST}}, \mathrm{LCP}\right)=0.44\right.$, $P=0.045$ ) (Figure 4B). There was no correlation with the other three resistance surfaces, in which the resistance values of host and road landscapes were higher than those of nonhost landscapes (except roads). This result suggested that at the fine scale $(<10 \mathrm{~km})$, the genetic differentiation of $M$. alternatus could not be determined by distance alone, although landscape types could have an effect. Among the landscapes, the host landscapes and roads had low resistance to local dispersal; whereas nonhost landscapes were more likely to inhibit movement in this species.

The top ten models in the LCTA of the two areas all demonstrated that $P$. massoniana, mixed forests with hosts, P. elliottii, and roads could facilitate the dispersal of M. alternatus (Table 3), which is also consistent with the LCP model in which the host and road landscapes had a lower resistance value. In Shunchang, the top model showed that $P$. massoniana was the most suitable dispersal habitat for this species, with the transect width of $600 \mathrm{~m}$ and the landscape variable of $P$. elliottii, which could facilitate gene flow (Table 3). However, in the fifth to tenth models, except for the eighth model in which roads had a positive effect, the other models all showed that both farmland and urban landscapes had a negative effect on gene flow (Table 3). In Xiapu, the top model suggested that mixed forest with hosts was the most suitable dispersal habitat for this species, with the transect width of $600 \mathrm{~m}$ and the landscape variable of urban, which had a negative effect on gene flow with the highest resistance value of $2^{9}$ (Table 3). The second and third models also showed that urban landscapes inhibited gene flow (Table 3). In the fifth to eighth models, P. elliottii was also a suitable habitat for this species to disperse, whereas $C$. lanceolata had a negative effect on gene flow (Table 3). Overall, in the two regions, the host and road landscapes were likely conducive to the dispersal 
of $M$. alternatus at a fine scale, whereas the nonhost landscapes had significant negative effects on dispersal and gene flow in this species.

\subsection{Influence of landscape on genetic diversity}

Analysis of the db-RDA model in Shunchang County showed that different landscape types had significant effects on the genetic diversity at three scales (Table 4). At the three scales of $300 \mathrm{~m}, 800 \mathrm{~m}$, and 1,000 m, the percentage of $P$. massoniana was significantly related to the genetic diversity of this species $(P(300 \mathrm{~m})=$ $0.031 ; P(800 \mathrm{~m})=0.022 ; P(1,000 \mathrm{~m})=0.006)$, explaining $47.478 \%, 45.730 \%$, and $43.342 \%$ of the variation, respectively (Table 4). Urban landscape was significantly correlated with the genetic diversity only at 800 $\mathrm{m}(P=0.046)$, whereas mixed forest with hosts had significant effects at scales of $800 \mathrm{~m}$ and $1,000 \mathrm{~m}(P$ $(800 \mathrm{~m})=0.038 ; P(1,000 \mathrm{~m})=0.031)$. At the $1,000 \mathrm{~m}$ scale, additional types of landscapes had significant correlations, including $P$. elliottii $(P=0.04)$, farmland $(P=0.018)$, and roads $(P=0.046)$ (Table 4$)$. In Xiapu, in addition to the influence of $P$. massoniana at the three scales, other landscape types at different scales also showed significance (Table 5 ). At the $800 \mathrm{~m}$ scale, $P$. elliottii was significantly correlated with the genetic diversity $(P=0.019)$, explaining $23.237 \%$ of the variation (Table 5$)$. At the $1,000 \mathrm{~m}$ scale, similar to Shunchang, there were more relevant landscape variables than at the two smaller scales, primarily including mixed forest with hosts $(P=0.032)$, roads $(P=0.032)$, farmland $(P=0.007)$, and urban $(P=0.041)$ (Table 5). In both areas, the different landscape types could affect the genetic diversity of $M$. alternatus , and the number of landscape types with effects increased with the increase in scale.

GAM analysis was performed to explain the nonlinear relationship in the db-RDA analysis. According to the results, the landscape variables fit well on the first two dimensions of the PCoA ordination (Figures 5 (Shunchang) and 6 (Xiapu)). Pinus massoniana increased gradually with the first PCoA axis or the second axis in both areas, indicating that $P$. massoniana was positively correlated with genetic diversity (Figure $5 \mathrm{~A}, \mathrm{~B}, \mathrm{E}$; Figure 6A, B, E). The landscape types that increased along the first PCoA axis also included roads in Shunchang (Figure 5I), whereas mixed forest with hosts and P. elliottiimainly increased with the second PCoA axis (Figure 5C, F, G). In Xiapu, mixed forest with hosts at the $800 \mathrm{~m}$ scale and P. elliottii and mixed forest with hosts at the 1,000 $\mathrm{m}$ scale also increased with the first PCoA axis (Figure 6C, D, F, $\mathrm{H}$ ). Urban decreased with the second PCoA axis in both areas (Figure 5D; Figure 6G), whereas farmland decreased with the first PCoA axis or the second axis (Figure 5H or Figure 6I), which indicated that the genetic diversity was negatively correlated with urban and farmland landscapes.

\section{DISCUSSION}

M. alternatus is the primary beetle vector of PWD in Asia, a major disease invading the forests. This study describes the first of the population structure of $M$. alternatus at intermediate and fine scales using whole-genome resequencing. In addition, the relationships between host and nonhost landscapes and this species were analyzed at a fine scale, which clarified the influence of multiple scales and different landscape types on dispersal behavior, gene flow, and genetic diversity. The results suggested that host forests could facilitate gene flow and dispersal of this species in a heterogeneous landscape and that human-mediated actions via roads were also conducive to dispersal. However, nonhost forest, urban, and farmland landscapes had negative effects on gene flow and dispersal. The different responses of M. alternatus to the heterogeneous landscapes indicate the importance of fully considering tree species and human-mediated landscapes when designing and managing forests and also suggest that PWD can be predicted and controlled in advance by determining the distribution of landscape types.

\subsection{Method of data analysis and model selection of landscape genetics with whole-genome resequencing}

The common markers in landscape genetics are microsatellites, mitochondrial DNA, amplified fragment length polymorphisms, and the Y chromosome (Manel, Schwartz, Luikart, \& Taberlet, 2003). In recent years, single nucleotide polymorphisms (SNPs) have become another major and widely used marking method. The greatest advantage and characteristic of SNPs is that the number of polymorphic sites increases greatly compared with that of other molecular markers. However, the increase in number of markers also increases 
the difficulty and the time needed for data analysis. Therefore, by selecting the correct analysis tool, the genetic model in whole-genome resequencing can be accurately obtained and the analysis time effectively shortened. Pairwise estimation of $\mathrm{F}_{\mathrm{ST}}$ is an important parameter in population genetic analysis that can conveniently summarize the population structure (Weir \& Cockerham, 1984). Pairwise $F_{S T}$ is generally calculated using GENEPOP (Rousset, 2008), the R package adegenet, or GenAlEx 6.5 (Peakall \& Smouse, 2012). In this study, after filtering, 4,152,751 SNPs were obtained in Shunchang and 3,298,993 SNPs were obtained in Xiapu. Then, the $\mathrm{R}$ package adegenet was used to calculate pairwise $\mathrm{F}_{\mathrm{ST}}$; however, the calculation required a long time, approximately one month. Therefore, the same data were used to calculate $\mathrm{F}_{\mathrm{ST}}$ through 5,000-bp windowing in vcftools software (Auton \& Marcketta, 2015), and the calculation required only $7 \mathrm{~h}$, which showed that using this method to calculate pairwise $\mathrm{F}_{\mathrm{ST}}$ could effectively shorten the calculation time.

Observed $\left(\mathrm{H}_{\mathrm{O}}\right)$ and expected $\left(\mathrm{H}_{\mathrm{E}}\right)$ heterozygosity, fixation index $\left(\mathrm{F}_{\mathrm{IS}}\right)$, allele diversity $(\mathrm{A})$, and mean number of alleles per locus $(\mathrm{K})$ are also important parameters in population genetic analysis, which can be calculated by software such as Arlequin 3.11 (Excoffier, Laval, \& Schneider, 2005), GENETIX 4.05 (Belkhir, Borsa, Chikhi, Raufaste, \& Bonhomme, 2004), or ADZE 1.0 (Szpiech, Jakobsson, \& Rosenberg, 2008). The commonly used software for calculating these parameters in Restriction-site associated DNA sequencing (RAD-seq) or Genotyping by sequenceing (GBS) is GenAlEx 6.5, but because the number of SNPs in wholegenome resequencing is usually a hundred times that of RAD-seq or GBS, GenAlEx 6.5 did not appear to be able to support such a large data set. Therefore, in this case, Metapop2 software (Lopez-Cortegano et al., 2019) was selected, which can not only calculate the complete genetic diversity but can also effectively analyze a large number of SNPs (e.g., >100,000 SNPs) in the latest optimized version. The software calculated the population genetic parameters in a total of $60 \mathrm{~h}$, which indicated that Metapop2 can effectively analyze millions or even tens of millions of SNPs in a short time.

To quantify the landscape structure and determine its effect on population genetics we used method of least-cost path based on resistance surface or straight-line transects (Spear et al., 2010). To eliminate the shortcomings of those two methods, Strien et al. (2012) developed the least-cost transect analysis (LCTA) by combining the two methods. While realizing objectivity, this analysis can also use buffers to form transect widths to quantify the proportions of each of the landscape types. In this study, LCTA was performed at a fine scale $(<10 \mathrm{~km})$ based on whole-genome resequencing, which clearly revealed the relationships between different tree types, urban areas, roads, and farmland and the dispersal and gene flow of $M$. alternatus . Thus, this analysis was effective with SNP markers and could identify the effects of landscape types at a fine scale. Cleary et al. (2017) used this analysis to describe the landscape genetics of two frugivorous bats under agricultural intensification and also obtained a better interpretation of effects. The db-RDA model also effectively described landscape genetics at a fine scale. This model breaks through the limitation that the existing method of RDA can only be performed by using Euclidian distance and allows the use of BrayCurtis or other ecologically meaningful measures (Legendre \& Anderson, 1999). The LCTA and db-RDA well explained the effects of different landscape types on $M$. alternatus at a fine scale, and because the results obtained by the two models were relatively consistent, both are applicable to landscape genetics at a fine scale under whole-genome resequencing.

\subsection{Population structure of $M$. alternatus at different scales}

The analysis of population structure at different scales revealed that there was obvious differentiation among populations at the intermediate scale $(>250 \mathrm{~km})$; whereas the difference at the fine-scale $(<10 \mathrm{~km})$ was weak but still had certain influence (Figure 2,3). The phylogenetic tree, PCA, and ADMIXTURE all showed that the two areas had different populations of $M$. alternatus, indicating that natural dispersal and gene flow at the intermediate scale were difficult. In the study of other species, the geographical distance and the genetic distance also are strongly correlated, and the geographical distance can also affect the genome-wide variation (Bay et al., 2018). This result demonstrates that the natural spread of M. alternatuscan be isolated at a distance of more than $250 \mathrm{~km}$, which also implies that the PWD can not be transmitted naturally at this distance. At the same time, further study are required to collect some populations at the scale of $10-250 \mathrm{~km}$ , so as to analyze the influence of this range on the spread of M. alternatus . 
In the analysis of genetic structure and diversity at the fine-scale, the results indicated that the populations in Shunchang and Xiapu were composed of two subpopulations, although the difference level within each subpopulation was not high (Figure 3; Table 2). According to the Mantel test, there was no significant correlation between genetic distance and IBD at the fine scale (Figure 4A). In Monochamusspecies, the flight distance is up to $22 \mathrm{~km}$ in the field, and based on a combination of flight mill and mark-releaserecapture experiments, the cumulative flying distance averages $63 \mathrm{~km}$ by the end of the adult stage in these species (Takasu et al., 2000; David, Giffard, Piou, \& Jactel, 2014; Robinet et al., 2019). As a result, strong inbreeding occurs in populations, leading to weak local genetic structure (Kawai et al., 2006; Shoda-Kagaya, 2007; Haran et al., 2015). Indeed, in this study, the genetic structure of the populations was weak at the fine-scale. The distribution of the host may also lead to the weakening of the population genetic structure. According to other studies, as long as the landscape type contains sufficient hosts for a species to inhabit and forage, the genetic structure may be insignificant at a distance of more than $120 \mathrm{~km}$ (McCulloch et al., 2013). In Shunchang and Xiapu, the landscape type was primarily forest, and there were many $P$. massoniana and P. elliottii distributed in the forest landscape. Because these tree species are important hosts of $M$. alternatus, the two species likely facilitate the dispersal of the beetle, and as a result, the genetic structure was poorly defined at the fine-scale. Although the geographic distance can have an important effect on the genetic structure of a species at large scales, differences in the genetic structure and obstruction of gene flow at a fine scale may be more affected by landscape types than by the geographic distance alone (Aurelie et al., 2017). Thus, with the increase in landscape scale, the influence of the geographical distance on the natural dispersal of $M$. alternatus was also increased, whereas at a fine scale, the influence of landscape types was greater than that of distance.

\subsection{Different effects of nonforest landscapes on gene flow and dispersal}

Urban landscapes are generally considered to be barriers to gene flow, and an increase in farmland landscapes can also directly or indirectly negatively affect the ecological processes and dispersal of many species (Butler, Vickery, \& Norris, 2007; Johnson \& Munshi-South, 2017; Lane-Degraaf, Fuentes, \& Hollocher, 2014; Ruell et al., 2012; ). According to the Mantel test of the correlation between the LCP of multiple resistance surfaces and the genetic distance, they were significantly correlated only when the urban and farmland landscapes were given high resistance values (Figures 4A, B). By contrast, no significant correlations were obtained with the other three resistance surfaces in which low resistance was given to urban and farmland landscapes (Supporting information Figure S3). Thus, by acting as barriers, urban and farmland landscapes played an important role in the dispersal and the gene flow of $M$. alternatus. This effect is possibly due to the limited food sources of the species in cities and farmland. Moreover, the use of pesticides in farmlands can also affect insects (Sonoda, Izumi, Kohara, Koshiyama, \& Yoshida, 2011), likely affecting the identification of hosts by M. alternatus and inhibiting dispersal.

Notably, the LCTA, in which the resistance value was objectively defined, also indicated that urban and farmland landscapes had a negative effect on gene flow (Tabel 3). Especially in Xiapu, the best three models in the LCTA showed that urban landscapes inhibited gene flow. In addition, the GAM model also suggested that urban and farmland landscapes were negatively correlated with genetic diversity at the 800 to $1,000-\mathrm{m}$ scale (Figure 6). Urbanization is one of the important factors that cause the loss of species habitat as well as forest fragmentation and the gradual but eventual disappearance of small areas of forest (Caspersen \& Olafsson, 2010), and the distribution of farmland destroys the continuity of host distribution. Because of the decline in forest coverage and the disappearance of host continuity, the population of $M$. alternatus may be separated to form isolated populations, thus reducing the gene flow. Indeed, farmland can directly affect the distribution and spread of insects and even hinder insect migration, which has important effects on population dynamics (Ge, Ou, \& Men, 2016). In a study on other species of Monochamus, the flying time of this species was short, sometimes only $1 \mathrm{~km}$ (David, 2014), so the farmland and urban landscapes at the scale of 800 to $1,000 \mathrm{~m}$ would most likely be barriers due to the unwillingness to fly. Thus, at a fine-scale, urban and farmland landscapes distributed are important barriers to dispersal and migration in this species.

Corridors in landscapes can promote the dispersal of species among different landscape types (Lapolla, 1993; 
Nicholls, Parrella, \& Altieri, 2001). Among nonforest landscapes, roads are very important corridors, and especially in areas with high landscape diversity, road patches can often play a role in connectivity. The fourth model of the LCTA in Shunchang showed that roads were the most suitable dispersal habitat for this species (Table 3). The LCP model showed that roads had the same low resistance value as other host landscapes (Figure 4C). The db-RDA and GAM models also indicated that roads were positively correlated with genetic diversity (Figure 5, 6; Table 4, 5). These results all suggest that roads are important and promote the dispersal of $M$. alternatus in a heterogeneous landscape. Although the existence of road networks can inhibit the dispersal and gene flow in some other species (Garcia-Gonzalez, Campo, Pola, \& Garcia-Vazquez, 2012; Hartmann, Steyer, Kraus, Segelbacher, \& Nowak, 2013), M. alternatus has the characteristic of the human-mediated movement, such as in the transport of infested wood from one area to another, including lumber and wood packaging material (Haack, 2006; Ye, 2019). This type of movement may cause the dispersal of this species in heterogeneous landscapes and may even lead to long-distance transmission. In a previous study on the genetic structure of $M$. alternatus, the road transportation system was also found to promote the dispersal of this species in mainland China (Hu, Ning, Fu, \& Haack, 2013). Therefore, roads can facilitate dispersal and gene flow of M. alternatus in heterogeneous landscapes by promoting long-distance, human-mediated transport.

\subsection{Relationships between detailed forest landscapes and population structure of M. alternatus}

This study showed that $P$. massoniana, $P$. elliottii, and mixed forest with hosts had the lowest resistance values and were the most suitable habitats for dispersal, whereas $C$. lanceolata had a negative effect on the gene flow (Table 3, 4,5). The db-RDA and GAM models also indicated that P. massoniana, P. elliottii, and mixed forest with hosts could promote genetic diversity and that $P$. massoniana had significant influence at each scale (i.e., $300 \mathrm{~m}, 800 \mathrm{~m}, 1,000 \mathrm{~m}$ ). Pinus massoniana and P. elliottii are important host tree species of M. alternatus (Hao, Zhang, Dai, \& Wan, 2005; Li, Xu, \& Zhang, 2003), and therefore, the three forest landscapes with hosts showed a promoting effect. By contrast, C. lanceolata was not a food source and was also the least preferred species of the tree species(Tu et al., 2019), indicating that the distribution of $C$. lanceolata could greatly hinder the dispersal of $M$. alternatus.

The promoting effects of hosts observed in this study are not supported by results in previous studies based on microsatellites in M. galloprovincialis (Haran et al., 2017; Koutroumpa, Rougon, Bertheau, Lieutier, \& Roux, 2013). However, another study found that the distribution of hosts could increase the gene flow of $M$. galloprovincialis on both sides of a mountain range (Haran, Roques, Barnard, Robine, \& Roux, 2015), and in China, the occurrence area of PWD is also significantly positively correlated with that of the host (Bai et al., 2015). The distribution of hosts most likely has different effects on Monochamus because of several reasons. First, there are different species of beetles in the same genus Allison, Strom, Sweeney, \& Mayo, 2019), and adult M. alternatus in forests also behave differently, depending on the stage (e.g., spawning period and mating period). Second, even when all forests have hosts, the tree age, height, canopy density, tree potential, and other factors may determine whether hosts inhibit or facilitate the dispersal of this species (Ding, Lv, Han, Pu, \& Wu, 2001; Jiang, Wan, Yao, Xu, \& Li, 2020). Last, the role of hosts is also closely related to the landscape scale. Therefore, more in-depth and detailed study and discussion on the influence of hosts are necessary.

Mixed forests are generally considered better able to resist and hinder forest pests than single stands, However, not all mixed forests have this effect, and the specific tree species, growth rates, and their relative proportions within and between stands in mixed forests must be fully considered (Damien et al., 2016). In this study, the mixed forest with hosts did not act as barriers to M. alternatus but had a certain promoting effect on its dispersal (Table 3, 4, 5; Figure 5,6), which was probably related to the partial distribution of P. massoniana in the mixed forest. Indeed, in some studies, PWD was more likely to occur in stands mixed with other tree species (Nakamura, Togashi, \& Takahashi, 1997; Togashi, Aida, Nakamura, Horikoshi, \& Takahashi, 1997). Haran et al. (2017) also suggest that a low density of pine trees is not a barrier to the dispersal of a species in the same genus, $M$. galloprovincialis. Thus, even when there are other tree species in a mixed forest or when the proportion of host trees is reduced because of other tree species, the dispersal 
of this species can be facilitated as long as there are host trees.

\section{ACKNOWLEDGMENTS}

This work was funded by the National Key Research and Development Program of China (grant number 2017YFD0600105), National Natural Science Foundation of China (grant numbers U1905201 and 31601905), Science and Technology Program of Fujian Province (grant number 2018N5002), Forestry Science Research Project of Fujian Forestry Department (grant number Minlinke [2017] 03).We are very grateful to Jianghua Sun (State Key Laboratory of Integrated Management of Pest Insects and Rodents, Institute of Zoology, Chinese Acade my of Sciences, Beijing, China) for help and support in this study.We warmly thank Key Laboratory of Integrated Pest Management in Ecological Forests, Fujian Province University for providing experimental environment, as well as thank Shunchang County Forestry Bureau and Xiapu County Forestry Bureau for providing research areas and helping to complete the collection of all samples.

\section{REFERENCES}

Adriaensen, F., Chardon, J. P., Blust, G. D., Swinnen, E., Villaba, S., Gulinck, H., \& Matthysena, E. (2003). The application of 'least-cost' modelling as a functional landscape model. Landscape and Urban Planning, 64(4), 233-247. https://doi.org/10.1016/S0169-2046(02)00242-6.

Alexander, D. H., Novembre, J., \& Lange, K. (2009). Fast model-based estimation of ancestry in unrelated individuals. Genome Research, 19(9), 1655-1664. https://doi.org/10.1101/gr.094052.109.

Allison, J., Strom, B., Sweeney, J., \& Mayo, P. (2019). Trap deployment along linear transects perpendicular to forest edges: impact on capture of longhorned beetles (Coleoptera: Cerambycidae). Journal of Pest Science, 92, 299-308. https://doi.org/10.1007/s10340-018-1008-7.

Akbulut, S., \& Stamps, W. T. (2011). Insect vectors of the pinewood nematode: a review of the biology and ecology of Monochamusspecies. Forest Pathology, 42(2), 89-99. https://doi.org/10.1111/j.14390329.2011.00733.x.

Aurelie, K., Peterman, W., Eraud, C., Faivre, B., Navarro, N., \& Garnier, S. (2017). Landscape genetic analyses reveal fine-scale effects of forest fragmentation in an insular tropical bird. Molecular Ecology, 26(19), 4906-4919. https://doi.org/10.1111/mec.14233.

Auton, A., \& Marcketta, A. (2015). VCFtools. (software). https://vcftools.github.io/index.html.

Bai, L., Tian, C.M., Hong, C. H., Kang, F. F., Chen, J. Y., Song, D. W., \& Liu, H. G. (2015). The relationship between pine forest landscape patterns and pine wilt disease in Yichang, Hubei Province. Acta Ecologica Sinica. 35(24), 8107-8116. https://doi.org/10. 5846 /stxb201406161248.

Barbosa, P., Hines, J., Kaplan, I., Martinson, H., Szczepaniec, A., \& Szendrei Z. (2009). Associational Resistance and Associational Susceptibility: Having Right or Wrong Neighbors. Annual Review of Ecology, Evolution, and Systematics, 40(1), 1-20. https://doi.org/10.1146/annurev.ecolsys.110308.120242.

Bay, R. A., Harrigan, R. J., Le Underwood, V ., Gibbs, H. L., Smith, T.B., \& Ruegg, K. B. (2018). Genomic signals of selection predict climate-driven population declines in a migratory bird. Science, 359(6371), 83-86. https://doi.org/10.1126/science.aan4380.

Belkhir, K., Borsa, P., Chikhi, L., Raufaste, N., \& Bonhomme, F. (2004). GENETIX4. 05, logiciel sous Windows TM pour la genetiquedes populations. Laboratoire Genome, Populations, Interactions, CNRS UMR 5000: Universite de Montpellier II, Montpellier (France). http://www.univmontp2.fr/ genetix/genetix/genetix.htm.

Beyer, H. L. (2015) . Geospatial Modelling Environment (Version 0.7.4.0). (software). http//www.spatialecology.com/gme

Butler, S. J., Vickery, J. A., \& Norris, K. (2007). Farmland Biodiversity and the Footprint of Agriculture. Science, 315(5810), 381-384. https://doi.org/10.1126/science.1136607. 
Caspersen, O. H., \& Olafsson, A.S. (2010). Recreational mapping and planning for enlargement of the green structure in greater Copenhagen. Urban Forestry \& Urban Greening, 9(2), 101-112. https://doi.org/10.1016/j.ufug.2009.06.007.

Clarke, R. T., Rothery, P., \& Raybould, A. F. (2002). Confidence limits for regression relationships between distance matrices: estimating gene flow with distance. Journal of agricultural biological \& environmental statistics, 7(3), 361-372.https://doi.org/10.1198/108571102320.

Cleary, K. A., Waits, L. P., \& Finegan, B. (2017). Comparative landscape genetics of two frugivorous bats in a biological corridor undergoing agricultural intensification. Molecular Ecology, 26(18), 4306-4317. https://doi.org/10.1111/mec.14230.

Damien, M., Jactel, H., Meredieu, C.Regolini, M., Halder, I.V \& Castagneyrol, B. (2016). Pest damage in mixed forests: Disentangling the effects of neighbor identity, host density and host apparency at different spatial scales. Forest Ecology \& Management, 378, 103-110. https://doi.org/10.1016/j.foreco.2016.07.025.

David, G., Giffard, B., Piou, D., \& Jactel, H. (2014). Dispersal capacity of Monochamus galloprovincialis , the European vector of the pine wood nematode, on flight mills. Journal of Applied Entomology, 138(8), 566-576. https://doi.org/10.1111/jen.12110.

David, G., Giffard, B., Piou, D., Roques, A., \& Jactel, H.(2016). Potential effects of climate warming on the survivorship of adult Monochamus galloprovincialis. Agricultural \& Forest Entomology, 19(2), 192-199. https://doi.org/10.1111/afe.12200.

David, G. (2014). Etude des capacites de dispersion de Monochamus galloprovincialis vecteur du nematode du pin Bursaphelenchus xylophilus (PhD thesis). Universite de Bordeaux, France. 159 pp. https://tel.archives-ouvertes.fr/tel-01243203.

Damien, M., Jactel, H., Meredieu, C., Regolini, M., Halder I.V., \& Castagneyrol, B. (2016) . Pest damage in mixed forests: Disentangling the effects of neighbor identity, host density and host apparency at different spatial scales. Forest Ecology \& Management, 378, 103-110. https://doi.org/10.1016/j.foreco.2016.07.025.

Ding, Y. Z., Lv, C. H., Han, B., Pu, H. P., \& Wu, M. L. (2011). Relationship between growth potential of pine, population density of Monochamus alternatus and pathogenicity of Bursaphlenchus xyloophilus. Chinese journal of applied ecology, 12(3), 351-354. https://doi.org/10.1007/s11769-001-0027-z.

Excoffier, L., Laval, G., \& Schneider, S. (2004). ARLEQUIN ver. 3.0: an integrated software package for population genetics data analysis. Evolutionary bioinformatics, 1, 47-50. http://cmpg.unibe.ch/software/arlequin3.

Foley, J. A. (2005). Global consequences of land use. Science, 309(5734), 570-574. https://doi.org/10.1126/science.1111772.

Fontaine, B., Bergerot, B., Le Viol, I., \& Julliard, R. (2016). Impact of urbanizaton and gardening practces on common buterfly communites in France. Ecology and Evoluton, 6(22): 8174-8180. https://doi.org/10.1002/ece3.2526.

Garcia-Gonzalez, C., Campo, D., Pola, I. G., \& Garcia-Vazquez, E.(2012). Rural road networks as barriers to gene flow for amphibians: Species-dependent mitigation by traffic calming. Landscape \& Urban Planning, 104(2):0-180. https://doi.org/10.1016/j.landurbplan.2011.10.012.

Ge, F., Ou, Y. F., \& Men, X. Y. (2007). Ecological Effects of Regional Agricultural Landscape on Insect and Its Prospect. Bulletin of the Chinese academy of sciences, 32(8), 32-37. https://doi.org/10.16418/j.issn.10003045.2017.08.004.

Goslee, S. C., \& Urban, D. L. (2007). The ecodist package for dissimilarity-based analysis of ecological data. Journal of statal software, 22(7), 1-19. https://doi.org/10.18637/jss.v022.i07. 
Gurka, M. J. (2006). Selecting the best linear mixed model under REML. The American Statistician, 60, 19-26. https://doi.org/10.2307/27643722.

Haack, R. A. (2006). Exotic bark- and wood-boring Coleoptera in the United States: recent establishments and interceptions. Revue Canadienne De Recherche Forestiere, 36(2), 269-288. https://doi.org/10.1139/x05249.

Hao, D. J., Zhang, Y. H., Dai, H. G., \& Wan, Y. (2005). Oviposition preference of Monochamus alternatus Hope ( Coleoptera:Cerambycidae) to host plants. Acta Entomologica Sinica, 48(3), 460-464. https://doi.org/10.16380/j.kcxb.2005.03.024.

Haran, J., Jerome, R., Tellez, D., \& Roques, A. (2017). Phylogeography of Monochamus galloprovincialis, the European vector of the pinewood nematode. Journal of Pest Science, 7, 1-11. https://doi.org/10.1007/s10340-017-0878-4.

Haran, J., Roques, A., Barnard, A., Robinet, C., \& Roux, G. (2015). Altitudinal barrier to the spread of an invasive species: could the Pyrenean chain slow the natural spread of the pine wood nematode? PLOS ONE, 10(7):e0134126. https://doi.org/ 10.1371/journal.pone.0134126.

Haran, J., Rossi, J. P., Pajares, J., Bonifacio, L., Naves, P., Roques, A., \& Roux, G. (2017). Multi-scale and multi-site resampling of a study area in spatial genetics: Implications for flying insect species. PeerJ, 5(7), 5:e4135. https://doi.org/10.7717/peerj.4135.

Harri, V., Koricheva, J., \& Kai, R. (2007). Tree species diversity influences herbivore abundance and damage: meta-analysis of long-term forest experiments. Oecologia, 2007, 152(2), 287-298. https://doi.org/10.2307/40210897.

Hartmann, S. A., Steyer, K., Kraus, R. H. S., Segelbacher, G., \& Nowak, C. (2013). Potential barriers to gene flow in the endangered European wildcat (Felis silvestris). Conservation Genetics, 14(2), 413-426. https://doi.org/10.1007/s10592-013-0468-9.

Hu, S. J., Ning, T., Fu, D.Y., \& Haack, R.(2013). Dispersal of the Japanese Pine Sawyer, Monochamus alternatus (Coleoptera: Cerambycidae), in Mainland China as Inferred from Molecular Data and Associations to Indices of Human Activity. PLOS ONE, 8(2), e57568. https://doi.org/10.1371/journal.pone.0057568.

Javal, M., Lombaert, E., Tsykun, T., Courtin, C., Kerdelhue, C., Prospero, S., Roques, A., \& Roux, G. (2019). Deciphering the worldwide invasion of the Asian long-horned beetle: a recurrent invasion process from the native area together with a bridgehead effect. Molecular Ecology, 28(5), 951-967. https://doi.org/10.1111/mec.15030.

Javal, M., Roques, A., Haran, J., Herard, F., Keena, M., \& Roux, G. (2017). Complex invasion history of the Asian long-horned beetle: fifteen years after first detection in Europe. Journal of Pest Science, 92, 173-187. https://doi.org/10.1007/s10340-017-0931-3.

Jactel, H., Barbaro, L., Battisti, A., Bosc, A., Branco, M., Brockerhoff, E., Castagneyrol, B., Dulaurent, A. M., Hodar, J.A., Jacquet, J. S., Mateus, E., Paiva, M. R., Roques, A.,Samalens, J. C., Santos, H., \& Schlyter, F. (2015). Processionary moths and climate change: An update, spp, 265-310. https://doi.org/ 10.1007/978-94-017-9340-7_6.

Jactel, H., \& Brockerhoff, E. G. (2007). Tree diversity reduces herbivory by forest insects. Ecology Letter, 10(9), 835-848.https://doi.org/10.1111/j.1461-0248.2007.01073.x.

Jactel, H., Goulard, M., Menassieu, P., \& Goujon, G. (2002). Habitat diversity in forest plantations reduces infestations of the pine stem borer Dioryctria sylvestrella. Journal of Applied Ecology, 39(4), 618-628. https://doi.org/10.1046/j.1365-2664.2002.00742.x.

Jeffries, D. L., Copp, G. H., Handley, L. L, Olsen, H., Sayer, C. D., \& Hänfling, B. (2016). Comparing RADseq and microsatellites to infer complex phylogeographic patterns, an empirical perspective in the Crucian 
carp, Carassius carassius, L. Molecular Ecology, 25(13), 2997-3018. https://doi.org/10.1111/mec.13613.

Jiang, X. H., Wan, Z. C., Yao, J. F., Xu, C. F., \& Li, Y. L. (2020). Correspondence analysis of quantitative distribution of Monochamus alternatus and

environmental factors at middle and low elevation area of Mount Huangshan. Forest Pest and Disease, 39(2), 16-19. https://doi.org/10.19688/ j.cnki.issn1671-0886.20200003.

Johnson, M. T. J., \&, Munshi-South, J. (2017). Evolution of life in urban environments. Science, 358(6363), 607-607.https://doi.org/10.1126/science.aam8327.

Kawai, M., Shoda-Kagaya, E., Maehara, T., Zhou, Z. H., Lian, C. L., Iwata, R., Yamane, A., \& Hogetsu, T. (2006). Genetic structure of pine sawyer Monochamus alternatus (Coleoptera: Cerambycidae) populations in northeast Asia: consequences of the spread of pine wilt disease. Environmental Entomology, 35(2), 569-579. https://doi.org/10.1603/0046-225X-35.2.569.

Keller, D., Strien, M. J. V., \& Holderegger, R. (2012). Do landscape barriers affect functional connectivity of populations of an endangered damselfly? Freshwater Biology, 57(7), 1373-1384. https://doi.org/10.1111/j.1365-2427.2012.02797.x.

Koutroumpa, F. A., Rougon, D., Bertheau, C., Lieutier, F., \& Roux, G. (2013). Evolutionary relationships within European Monochamus(Coleoptera: Cerambycidae) highlight the role of altitude in species delineation. Biological Journal of the Linnean Society, 109(2), 354-376. https://doi.org/10.1111/bij.12042.

Lane-Degraaf, K. E., Fuentes, A., \& Hollocher, H. (2014). Landscape genetics reveal fine-scale boundaries in island populations of Indonesian long-tailed macaques. Landscape Ecology, 29(9), 1505-1519. https://doi.org/10.1007/s10980-014-0069-0.

Lapolla, V. (1993). Effects of corridor width and presence on the population dynamics of the meadow vole (Microtus pennsylvanicus). Landscape Ecology, 8(1), 25-37. https://doi.org/10.1007/BF00129865.

Legendre, P., \& Anderson, M. J. (1999). Distance-based redundancy analysis: Testing multispecies responses in multifactorial ecological experiments. Ecological Monographs, 69(1), 1-24. https://doi.org/10.1890/00129615(1999)069[0001:DBRATM]2.0.CO;2.

Lengyel, A., Podani, J. (2015). Assessing the relative importance of methodological decisions in classifications of vegetation data. Journal of Vegetation Science, 26(4), 804-815. https://doi.org/10.1111/jvs.12268.

Lian, J., \& Zhang, X. Y. (2005). Forest pest ecological control. Scientia Silvae Sinicae, 41(4), 168-176. https://doi.org/10.3321/j.issn:1001-7488.2005.04.029.

Li, H., \& Durbin, R. (2009). Fast and accurate short read alignment with Burrows-Wheeler transform. Bioinformatics, 25(14), 1754-1760.https://doi.org/10.1093/bioinformatics/btp324.

Li, H., Handsaker, B., Wysoker, A., Alec, W., Tim, F., \& Jue, R. (2009). The Sequence Alignment-Map format and SAMtools. Bioinformatics, 25(16), 2078-2079. https://doi.org/10.1093/bioinformatics/btp352.

Li, R. J., Xu, F. Y., \& Zhang, P. (2003). Host Preference by Monochamus alternatus (Hope) during Maturation Feeding on Pine Species and Masson Pine Provenances. Chinese Forestry Science \& Technology, 4, 95-102. https://doi.org/CNKI:SUN:ZGLK.0.2003-04-012.

Liu, Y., Chen, L., Duan, X. Z., Zhao, D. S., Sun, J. T \& Hong, S. Y. (2019). Genome-Wide Single Nucleotide Polymorphisms are robust in resolving fine-Scale population genetic structure of the small brown planthopper, Laodelphax striatellus (Fallén) (Hemiptera: Delphacidae). Journal of Economic Entomology, 112(5), 23622368. https://doi.org/10.1093/jee/toz145.

López-Cortegano, E., Pérez-Figueroa, A., \& Caballero, A.(2019). Metapop2: re-implementation of software for the analysis and management of subdivided populations using gene and allelic diversity. Molecular Ecology Resources, 19(4), 1095-1100. https://doi.org/10.1111/1755-0998.13015. 
Lu, M., Wingfield, M. J., Gillette, N., \& Sun J. (2011). Do novel genotypes drive the success of an invasive bark beetle-fungus complex? Implications for potential reinvasion. Ecology, 92(11), 2013-2019. https://doi.org/10.1890/11-0687.1.

Maehara, N., \& Futai, K. (1997). Effect of fungal interactions on the numbers of the pinewood nematode, Bursaphelenchus xylophilus(Nematoda: Aphelenchoididae), carried by the Japanese pine sawyer,Monochamus alternatus (Coleoptera: Cerambycidae. Fundamental \& applied nematology, 20(6), 611617. https://doi.org/10.1159/000157256.

Mack, R., Simberloff, D., Lonsdale, W. M., Evans, H., Clout, M., \& Bazzaz, F. A.. Biotic invasions: causes,epodemiology, global consequences, and control. Ecological Applications, 10(3), 689-710. https: //doi.org/10.2307/2641039.

Mamiya, Y., \& Shoji, T. (2009). Pathogenicity of the pinewood nematode,Bursaphelenchus xylophilus , to Japanese larch, Larix kaempferi, seedlings. Journal of Nematology, 41(2), 157-162. https://doi.org/10.1111/j.1600-0684.2009.00342.x.

Manel, S., Schwartz, M. K., Luikart, G., \& Taberlet, P. (2003). Landscape genetics: Combining landscape ecology and population genetics. Trends in Ecology \& Evolution, 18(4), 189-197. https://doi.org/10.1016/S01695347(03)00008-9.

McCulloch, E. S., Tello, J. S., Whitehead, A., Rolón-Mendoza, C. M. J., Maldonado-Rodríguez, M. C. D., \& Stevens, R. D. (2013). Fragmentation of Atlantic Forest has not affected gene flow of a widespread seeddispersing bat. Molrecular Ecology, 22(18), 4619-4633. https://doi.org/10.1111/mec.12418.

Mota, M. M., \& Vieira, P. (2008). Pine Wilt Disease: A Worldwide Threat to Forest Ecosystems. Springer Netherlands. https://doi .org/10.1007/978-1-4020-8455-3.

Nakamura, K., Togashi, K., \& Takahashi, F. (1997). Distance effect of co-occurring tree species on pine wilt disease incidence inPinus densifloraseedlings inoculated with Bursaphelenchus xylophilus . Ecological Research, 1997, 12(3), 265-275. https://doi.org/10.1007/bf02529456.

Nancy, M. E. H., Schmidt, T. L., Chung, J., Rooyen, A. V., Weeks, A. R., \& Hoffmann, A. A. (2020). Heterogeneous genetic invasions of three insecticide resistance mutations in Indo-Pacific populations of Aedes aegypti (L.). Molrecular Ecology. https://doi.org/10.1111/mec.15430.

Naves, P. M., Camacho, S., Sousa, E., \& Quartau, J. A. (2007). Transmission of the pine wood nematode Bursaphelenchus xylophilus through oviposition activity ofMonochamus galloprovincialis (Col., Cerambycidae). Journal of Applied Entomology, 131(1), 21-25. https://doi.org/10.1111/j.1439-0418.2006.01111.x.

Nicholls, C. I., Parrella, M., \& Altieri, M. A. (2001). The effects of a vegetational corridor on the abundance and dispersal of insect biodiversity within a northern California organic vineyard. Landscape Ecology, 16(2), 133-146. https://doi.org/10.1023/a:1011128222867.

Ortego, J., Bonal, R., \& Munoz, A. (2010). Genetic Consequences of Habitat Fragmentation in Long-Lived Tree Species: The Case of the Mediterranean Holm Oak (Quercus ilex, L.). Journal of Heredity, 101(6), 717-726. https://doi.org/10.1093/jhered/esq081.

Quayle, D., Regniere, J., Cappuccino, N., \& Dupont, A. (2003). Forest composition, host-population density, and parasitism of spruce budworm Choristoneura fumiferana eggs by Trichogramma minutum. Entomologia Experimentalis et Applicata, 107(3), 215-227. https://doi.org/10.1046/j.1570-7458.2003.00056.x.

Rašić, G., Filipović, I., Weeks, A. R., \& Hoffmann, A. A. (2014). Genome-wide SNPs lead to strong signals of geographic structure and relatedness patterns in the major arbovirus vector, Aedes aegypti. BMC Genomics, 15(1), 1-12. https://doi.org/10.1186/1471-2164-15-275.

Rellstab, C., Gugerli, F., Eckert, A.J., Hancock, A. M., \& Holderegger, R. (2015) .A practical guide to environmental association analysis in landscape genomics. Molecular Ecology, 24(17), 4348-4370. 
https://doi.org/10.1111/mec.13322.

Robinet, C., David, G., \& Jactel, H. (2019). Modeling the distances traveled by flying insects based on the combination of flight mill and mark-release-recapture experiments. Ecological Modelling, 402, 85-92. https://doi.org/10.1016/j.ecolmodel.2019.04.006.

Rod, P., \& Smouse, P. E. (2012). GenAlEx 6.5: genetic analysis in Excel. Population genetic software for teaching and research-an update. Bioinformatics, 28(19), 2537-9. https://doi.org/10.1093/bioinformatics/bts460.

Rousset, F. (2008). GENEPOP' 007: a complete re-implementation of the GENEPOP software for Windows and Linux. Molecular Ecology Resources, 8(1), 103-106. https://doi.org/10.1111/j.1471-8286.2007. 01931.x.

Ruell, E. W., Riley, S. P. D., Douglas, M. R., Antolin, M. F., Pollinger, J. R., Tracey, J. A., Lyren, L. M., Boydston, E. E., Fisher, R. N., \& Crooks, K. R. (2012). Urban Habitat Fragmentation and Genetic Population Structure of Bobcats in Coastal Southern California. American Midland Naturalist, 168(2), 265-280. https://doi.org/10.1674/0003-0031-168.2.265.

Shoda-Kagaya, E. (2007). Genetic differentiation of the pine wilt disease vector Monochamus alternatus (Coleoptera: Cerambycidae) over a mountain range revealed from microsatellite DNA markers. Bulletin of Entomological Research 97(2), 167-174. https://doi.org/10.1017/S000748530700483X.

Soliman, T., Mourits, M. C. M., Van der Werf, W., Hengeveld G. M., Robinet, C., \& Lansik, A. O. (2012). Framework for modeling economic impacts of invasive species, applied to pine wood nematode in Europe. PLoS ONE, 7(9), e45505. https://doi.org/10.1371/journal.pone.0045505.

Sonoda, S., Izumi, Y., Kohara, Y., Koshiyama, Y., \& Yoshida, H. (2011) . Effects of pesticide practices on insect biodiversity in peach orchards. Applied Entomology \& Zoology, 46(3), 335-342. https://doi.org/10.1007/s13355-011-0041-2.

Sousa, E., Bravo, M. A., Pires, J., Naves, P., Penas, A.C., Bonifacio, L., \& Mota, L . (2001). Bursaphelenchus xylophilus (Nematoda; Aphelenchoididae) associated with Monochamus galloprovincialis(Coleoptera; Cerambycidae) in Portugal. Nematology, 3(1), 89-91. https://doi.org/10.1163/156854101300106937.

Spear, S. F., Balkenhol, N., Fortin, M. J., Mcrae, B. H., \& Scribner, K. (2010). Use of resistance surfaces for landscape genetic studies: considerations for parameterization and analysis. Molecular Ecology, 19(17), 3576-3591. https://doi.org/10.1111/j.1365-294X.2010.04657.x.

Strien, M. J. V., Keller, D., \& Holderegger, R. (2012). A new analytical approach to landscape genetic modelling: least-cost transect analysis and linear mixed models. Molecular Ecology, 21(16), 4010-4023. https://doi.org/10.1111/j.1365-294x.2012.05687.x.

Sudhir, K., Glen, S., \& Koichiro, T. (2016). MEGA7: Molecular Evolutionary Genetics analysis version 7.0 for bigger datasets. Molecular Biology and Evolution, 3(7), 1870-1874. https://doi.org/10.1093/molbev/msw054.

Sun, J. H., Yuan, D. C., \& Ou, Y. H. (2002). Exotic forest pest invasion:A threat to forest ecosystems in China. Forest Pest And Disease, 21(6), 32-35. https://doi.org/10.3969/j.issn.1671-0886.2002.06.011.

Szpiech, Z.A., Jakobsson, M., \& Rosenberg, N.A. (2008). ADZE: a rarefaction approach for counting alleles private to combinations of populations. Bioinformatics Oxford, 24, 2498-2504. https://doi.org/10.1093/bioinformatics/btn478.

Takasu, F., Yamamoto, N., Kawasaki, K., Togashi, K., Kishi, Y., \& Shigesada, N. (2000). Modeling the expansion of an introduced tree disease. Biological Invasions, 2, 141-150. https://doi.org/10.1023/A:1010048725497. 
Togashi, K., Aida, K., Nakamura, K., Horikoshi, T., \& Takahashi, F. (1997). Different development of pine wilt disease in artificially infected Pinus thunbergii seedlings potted together with different tree species. Journal of Forest Research, 2(1), 39-43. https://doi.org/10.1007/BF02348261.

Tsykun, T., Javal, M., Hölling, D., Roux, G., \& Prospero, S. (2019). Fine-scale invasion genetics of the quarantine pest, Anoplophora glabripennis, reconstructed in single outbreaks. Scienfific Repots, 9, 19436. https://doi.org/10.1038/s41598-019-55698-3.

Turner, M. G . (1989). Landscape Ecology: The effect of pattern on process. Annual Review of Ecology \& Systematics, 20(1), 171-197. https://doi.org/10.1146/annurev.ecolsys.20.1.171.

Tu, Y. G., Li, Y., Yu, A. L., Xiong, D. Y., Que, S. Q., Wan, W. H., \& Jin, M. X. (2019). Feeding and oviposition preferences of Monochamus alternatus adults among different host plants. China Plant Protection, 39(5), 50-52. https://doi.org/10.3969/j.issn.1672-6820.2019.05.009.

Underwood, N., Inouye, B. D., \& Hambäck, P. A. (2014). A Conceptual Framework for Associational Effects: When Do Neighbors Matter and How Would We Know? Quarterly Review of Biology, 89(1):1-19. https://doi.org/10.1086/674991.

Van Etten, J. (2014). gdistance : distances and routes on geographical grids. R package version 1.1-5. http://CRAN.R-project.org/package=gdistance.

Walker, B. H., \& Steffen, W. (1996). An Overview of the implications of global change for natural and managed terrestrial ecosystems. Ecology And Scociety, 1(2), https://doi.org/10.5751/ES-00028-010202.

Weir, B. C., \& Cockerham, C. C. (1984). Estimating F-Statistics for the Analysis of Population Structure. Evolution, 38(6), 1358-1370. https://doi.org/10.1111/j.1558-5646.1984.tb05657.x.

Wu, S. Q., Yuan, W. M., Tian, X. J., Fan, B., Ye, J. R., \& Ding, X. L. (2013). Specific and functional diversity of endophytic bacteria from pine wood nematode Bursaphelenchus Xylophilus with different virulence. International Journal of Biological Sciences, 9(1), 34-44. https://doi.org/10.7150/ijbs.5071.

Yadav, S., Stow, A.J., \& Dudaniec, R.Y. (2019). Detection of environmental and morphological adaptation despite high landscape genetic connectivity in a pest grasshopper (Phaulacridium vittatum), Molecular Ecology, 28(14), 3995-3412. https://doi.org/10.1111/mec.15146.

Yang, J., Lee, S. H., Goddard, M. E., \& Visscher, P. M. (2011). GCTA: a tool for genome-widecomplex trait analysis. Am J Hum Genet, 88(1), 76-82. https://doi.org/10.1016/j.ajhg.2010.11.011.

Ye, J. R. (2019). Episemic status of pine wilt disease in China and its prevention and control techniques and counter measures. Scientia Silvae Sinicae, 55(9), 1-10. https://doi.org/10.11707/j.1001-7488.20190901.

Zhao, B. G., Futai, K., Sutherland, J.R., \& Takeuchi, Y. (2008). Pine wilt disease. Springer Japan. https://doi.org/10.1007/978-4-431-75655-2.

Zhao, L. L., Mota, M., Vieira, P., Butcher, R. A., \& Sun, J. H. (2013) .Interspecific communication between pinewood nematode, its insect vector, and associated microbes.Trends in parasitology, 30(6), 299-308. https://doi.org/10.1016/j.pt.2014.04.007.

Zhen, Y., Harrigan, R. J., Ruegg, K. C., Anderson, E. C., Ng, T. C., Lao, S., Lohmueller, K. E., \& Smith, T. B. (2017). Genomic divergence across ecological gradients in the Central African rainforest songbird (Andropadus virens). Molecular Ecology, 26(19), 4966-4977. https://doi.org/10.1111/mec.14270.

\section{DATA ACCESSIBILITY STATEMENT}

Whole-genome resequencing data is planned to be publicly accessed on NCBI in the form of VCF files (https://www.ncbi.nlm.nih.gov/). Genebank accession numbers will also provide.

\section{AUTHOR CONTRIBUTION}


YCL, SQW and FPZ designed the whole experiment. YCL, XHH and XQW were survey study area and collect samples. WLH performs data analysis of Whole-genome resequencing. YCL, XHH and XQW construction and analysis model. RW, XH, GHL, SGH, SQW and FPZ procured funding. CLL and RCL have modified the article. YCL finished writing with the participation of all authors, and all authors approved the manuscript.

\section{TABLES}

Table 1.-Sampling point information

Table 2.-Estimates of population diversity

Table 3.-Maximum-likelihood population effects models with genetic distance (FST) as the response variable and results from the least-cost transect analyses as the explanatory variables

Table 4.-Summary statistics for the db-RDA model of genetic diversity in Shunchang, influenced by the percentage of different landscapes in circular buffers with radii of $300 \mathrm{~m}, 800 \mathrm{~m}$, and 1,000 m

Table 5.- Summary statistics for the db-RDA model of genetic diversity in Xiapu, influenced by the percentage of different landscapes in circular buffers with radii of $300 \mathrm{~m}, 800 \mathrm{~m}$, and 1,000 m

\section{FIGURE LEGENDS}

Figure 1.-Landscape types and populations sampled across the Shunchang County and Xiapu County in China.

\section{A. Shunchang County; B. Xiapu County}

The intermediate scale with the two counties shaded is shown in the map below the fine scale maps of the two study areas, each with ten landscape types.

Figure 2.-Population structure analysis of $M$. alternatus at an intermediate scale.

Neighbor-joining phylogenetic tree of all individuals. (B) Principal component analysis of all individuals. (C) ADMIXTURE analysis, with only the $K$ with the smallest $C V$ error shown $(K=2)$. SC, Shunchang; XP, Xiapu.

Figure 3.-Smallest cross-validation error of genetic structure detected by ADMIXTURE at a fine scale $(\mathrm{K}=$ 2).

The two genetic clusters in Shunchang County (blue and green); (B) The two genetic clusters in Xiapu County (mint green and red). The size of each chart is proportional to the sample size. The gray area represents all forest habitats, and the white area represents other habitats.

Figure 4.-Mantel correlation tests between genetic distance and (A) Euclidian or (B) least-cost distance between pairs of populations.

Least-cost distances were calculated using the opinion method resistance surface relying on the land cover surface. Only the resistance surface 1 (B) and its resistance values (C) are shown, because the other three groups of resistance values were not significant.

Figure 5.-Principal coordinates analysis of predictor variables and fitted as trend surfaces a posteriori by generalized additive model in Shunchang County.

$300 \mathrm{~m}$, P. massoniana ; (B) $800 \mathrm{~m}$, P. massoniana ; (C) $800 \mathrm{~m}$, Mixed forest; (D) $800 \mathrm{~m}$, Urban; (E) 1,000 m, P. massoniana ; (F) 1,000 m, Mixed forest; (G) 1,000 m, P. elliottii ; (H) 1,000 m, Farmland; (I) 1,000 $\mathrm{m}$, Road.

Figure 6.-Principal coordinates analysis of predictor variables and fitted as trend surfaces aposteriori by generalized additive model in Xiapu County. 
(A) $300 \mathrm{~m}$, P. massoniana ; (B) $800 \mathrm{~m}$, P. massoniana ; (C) $800 \mathrm{~m}$, Mixed forest; (D) $800 \mathrm{~m}$, P. elliottii ; (E) 1,000 m,P. massoniana ; (F) 1,000 m, Mixed forest; (G) 1,000 m, Farmland; (H) 1,000 m, Road: (I) $1,000 \mathrm{~m}$, Urban.

Table 1. -Sampling point information

\begin{tabular}{lllll}
\hline Study location & Site & Sample no & Latitude $(\mathrm{N})$ & Longitude (E) \\
SC & SC1 & 7 & 26.78810278 & 117.7934222 \\
& SC2 & 9 & 26.79221944 & 117.8110306 \\
& SC3 & 12 & 26.810075 & 117.8108444 \\
& SC4 & 7 & 26.80866667 & 117.7933306 \\
& SC5 & 8 & 26.80754444 & 117.78365 \\
& SC6 & 10 & 26.81075556 & 117.77665 \\
& SC7 & 14 & 26.81578889 & 117.7851528 \\
& SC8 & 14 & 26.81764444 & 117.7789222 \\
& SC9 & 10 & 26.82101111 & 117.7741056 \\
& SC10 & 7 & 26.77182778 & 117.7358667 \\
& SC11 & 10 & 26.85954444 & 117.8003167 \\
SC12 & 7 & 26.87125278 & 117.7454056 \\
XP & XP1 & 10 & 26.989183 & 120.222639 \\
& XP2 & 10 & 26.990892 & 120.213067 \\
XP3 & 10 & 26.998219 & 120.194725 \\
& XP4 & 9 & 26.980986 & 120.171342 \\
XP5 & 10 & 26.986389 & 120.169403 \\
XP6 & 10 & 26.990178 & 120.162661 \\
XP7 & 9 & 27.001125 & 120.163372 \\
XP8 & 10 & 26.953933 & 120.176708 \\
XP9 & 10 & 26.963456 & 120.165219 \\
XP10 & 12 & 27.041250 & 120.142739 \\
\hline
\end{tabular}

Table 2.-Estimates of population diversity

\begin{tabular}{llllll}
\hline Location & Site & $\mathbf{H}_{\mathbf{E}}$ & $\mathbf{s}$ & $\mathbf{A}$ & $\mathbf{K}$ \\
SC & SC1 & 0.2228 & 0.8784 & 0.7637 & 1.794 \\
& SC2 & 0.2248 & 0.8799 & 0.7613 & 1.8529 \\
& SC3 & 0.2325 & 0.8772 & 0.766 & 1.9149 \\
& SC4 & 0.2208 & 0.8798 & 0.7629 & 1.7901 \\
& SC5 & 0.2328 & 0.875 & 0.7752 & 1.8448 \\
& SC6 & 0.2338 & 0.876 & 0.7709 & 1.8874 \\
& SC7 & 0.2383 & 0.8758 & 0.7726 & 1.9441 \\
& SC8 & 0.2351 & 0.8792 & 0.7666 & 1.9397 \\
& SC9 & 0.2304 & 0.8773 & 0.7638 & 1.8785 \\
XP & SC10 & 0.2246 & 0.8777 & 0.7677 & 1.7994 \\
& SC11 & 0.2293 & 0.8785 & 0.7652 & 1.8808 \\
& SC12 & 0.2242 & 0.8779 & 0.7655 & 1.798 \\
& XP1 & 0.2127 & 0.8861 & 0.7674 & 1.8696 \\
& XP2 & 0.2082 & 0.8885 & 0.7596 & 1.8601 \\
XP3 & 0.2097 & 0.8869 & 0.7639 & 1.84 \\
& XP4 & 0.2038 & 0.8886 & 0.7626 & 1.7693 \\
& XP5 & 0.2055 & 0.8893 & 0.756 & 1.8538 \\
& XP6 & 0.2043 & 0.8892 & 0.7575 & 1.8293
\end{tabular}




\begin{tabular}{lllll} 
XP7 & 0.2076 & 0.8879 & 0.7616 & 1.8362 \\
XP8 & 0.2074 & 0.889 & 0.7602 & 1.8596 \\
XP9 & 0.2015 & 0.8895 & 0.7554 & 1.7924 \\
XP10 & 0.2083 & 0.8889 & 0.7586 & 1.8973 \\
\hline
\end{tabular}

Note: Expected heterozygosity $\left(\mathrm{H}_{\mathrm{E}}\right)$, self-coancestry $(\mathrm{s})$, allelic diversity $(\mathrm{A})$, and mean number of alleles per locus $(K)$.

Table 3.-Maximum-likelihood population effects models with genetic distance $\left(\mathrm{F}_{\mathrm{ST}}\right)$ as the response variable and results from the least-cost transect analyses as the explanatory variables

\begin{tabular}{|c|c|c|c|c|c|}
\hline Location & Genetic differentiation & Dispersal habitat & Resistance level & Transect width (m) & Variables \\
\hline \multirow[t]{10}{*}{$\mathrm{SC}$} & $\mathrm{F}_{\mathrm{ST}}$ & P. massoniana & $2^{9}$ & 600 & P. elliottii ( \\
\hline & & P. massoniana & $2^{3}$ & 600 & P. elliottii ( \\
\hline & & P. massoniana & $2^{6}$ & 600 & P. elliottii ( \\
\hline & & Road & $2^{9}$ & 600 & P. elliottii ( \\
\hline & & Mixed forest & $2^{9}$ & 200 & Farmland (- \\
\hline & & Mixed forest & $2^{6}$ & 200 & Farmland (- \\
\hline & & P. massoniana & $2^{3}$ & 600 & Urban $(-)$ \\
\hline & & P. massoniana & $2^{6}$ & 400 & $\operatorname{Road}(+)$ \\
\hline & & Mixed forest & $2^{9}$ & 600 & Farmland (- \\
\hline & & P. massoniana & $2^{3}$ & 400 & Urban (-) \\
\hline \multirow[t]{10}{*}{$\mathrm{XP}$} & $\mathrm{F}_{\mathrm{ST}}$ & Mixed forest & $2^{9}$ & 600 & Urban (-) \\
\hline & & Mixed forest & $2^{9}$ & 400 & Urban (-) \\
\hline & & Mixed forest & $2^{9}$ & 200 & Urban (-) \\
\hline & & P. massoniana & $2^{9}$ & 600 & Farmland (- \\
\hline & & P. elliottii & $2^{6}$ & 400 & C. lanceolat \\
\hline & & P. elliottii & $2^{9}$ & 600 & C. lanceolat \\
\hline & & P. elliottii & $2^{9}$ & 400 & C. lanceolat \\
\hline & & P. elliottii & $2^{6}$ & 600 & C. lanceolat \\
\hline & & P. massoniana & $2^{3}$ & 200 & Farmland (- \\
\hline & & P. massoniana & $2^{6}$ & 600 & Urban (-) \\
\hline
\end{tabular}

Note: This table shows the top ten models of SC and XP based on AIC respectively. The variables in each model are positively correlated with "+" and negatively correlated with "-".

Table 4.-Summary statistics for the db-RDA model of genetic diversity in Shunchang, influenced by the percentage of different landscapes in circular buffers with radii of $300 \mathrm{~m}, 800 \mathrm{~m}$, and 1,000 m

\begin{tabular}{lllll}
\hline Circular buffer & Landscape & Explained variation \% & $\mathrm{F}$ & $\mathrm{P}$ \\
$300 \mathrm{~m}$ & \% P. massoniana & 47.478 & 9.6003 & $0.031^{*}$ \\
$800 \mathrm{~m}$ & \% P. massoniana & 45.730 & 37.230 & $0.022^{*}$ \\
& \% Mixed forest & 22.811 & 18.571 & $0.038^{*}$ \\
& \% Urban & 13.595 & 11.068 & $0.046^{*}$ \\
$1,000 \mathrm{~m}$ & \% P. massoniana & 43.342 & 132.812 & $0.006^{* *}$ \\
& \% Mixed forest & 13.450 & 40.448 & $0.031^{*}$ \\
& \% P. elliottii & 10.500 & 32.174 & $0.04^{*}$ \\
& \% Farmland & 18.292 & 56.054 & $0.018^{*}$ \\
& \% Road & 9.350 & 28.648 & $0.046^{*}$ \\
\hline
\end{tabular}


Note: significant $\left({ }^{*} P<0.05\right)$, the same bleow.

Table 5. Summary statistics for the db-RDA model of genetic diversity in Xiapu, influenced by the percentage of different landscapes in circular buffers with radii of $300 \mathrm{~m}, 800 \mathrm{~m}$, and 1,000 m

\begin{tabular}{lllll}
\hline Circular buffer & Landscape & Explained variation \% & $\mathrm{F}$ & $\mathrm{P}$ \\
$300 \mathrm{~m}$ & \% P. massoniana & 35.271 & 8.4176 & $0.047^{*}$ \\
$800 \mathrm{~m}$ & \% P. massoniana & 15.563 & 22.9195 & $0.031^{*}$ \\
& \% Mixed forest & 30.792 & 45.3488 & $0.01^{*}$ \\
& \% P. elliottii & 23.237 & 34.2221 & $0.019^{*}$ \\
$1,000 \mathrm{~m}$ & \% P. massoniana & 39.474 & 114.3156 & $0.003^{* *}$ \\
& \% Mixed forest & 8.214 & 23.7867 & $0.032^{*}$ \\
& \% Road & 8.185 & 23.7045 & $0.032^{*}$ \\
& \% Urban & 24.596 & 71.2305 & $0.007^{* *}$ \\
& \% Farmland & 6.557 & 18.9874 & $0.041^{*}$ \\
\hline
\end{tabular}

A

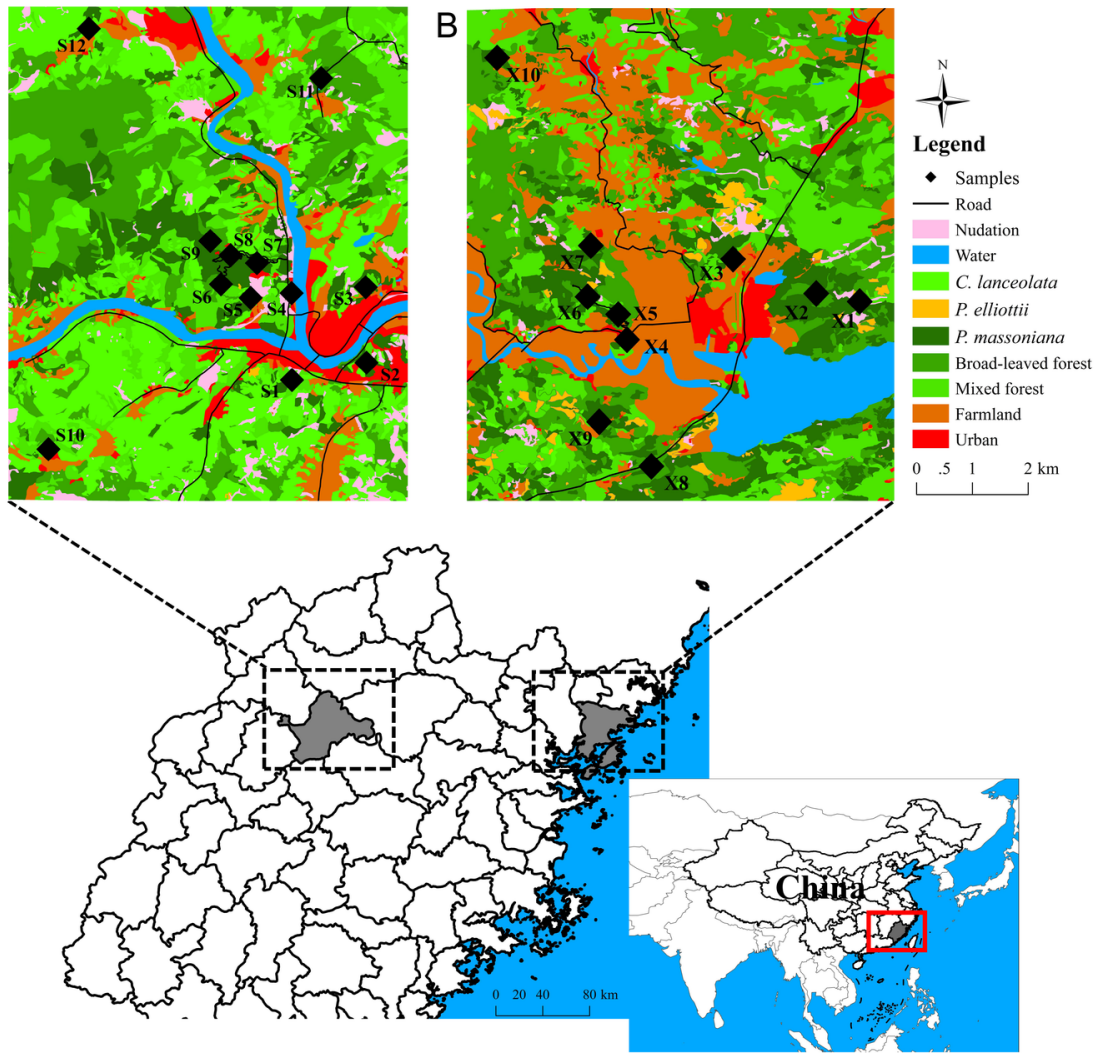

Figure 1.-Landscape types and populations sampled across the Shunchang County and Xiapu County in China.

\section{A. Shunchang County; B. Xiapu County}

The intermediate scale with the two counties shaded is shown in the map below the fine scale maps of the two study areas, each with ten landscape types. 


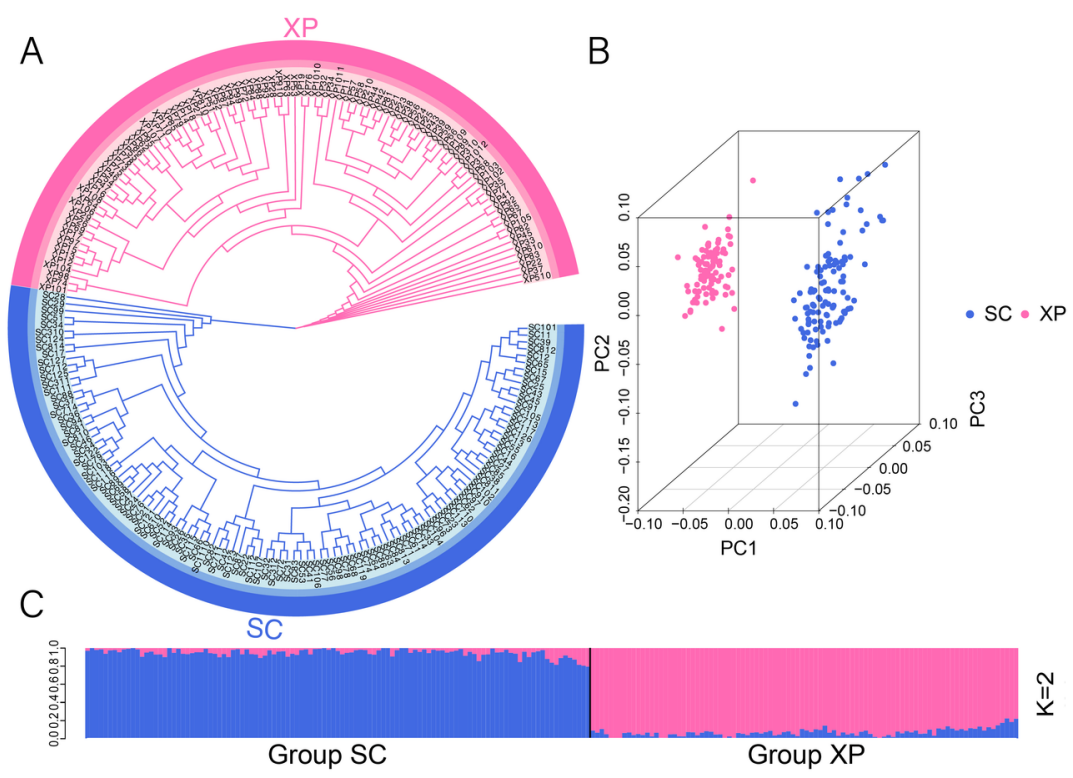

Figure 2.-Population structure analysis of $M$. alternatus at an intermediate scale.

Neighbor-joining phylogenetic tree of all individuals. (B) Principal component analysis of all individuals. (C) ADMIXTURE analysis, with only the $\mathrm{K}$ with the smallest $\mathrm{CV}$ error shown $(\mathrm{K}=2)$. SC, Shunchang; XP, Xiapu.
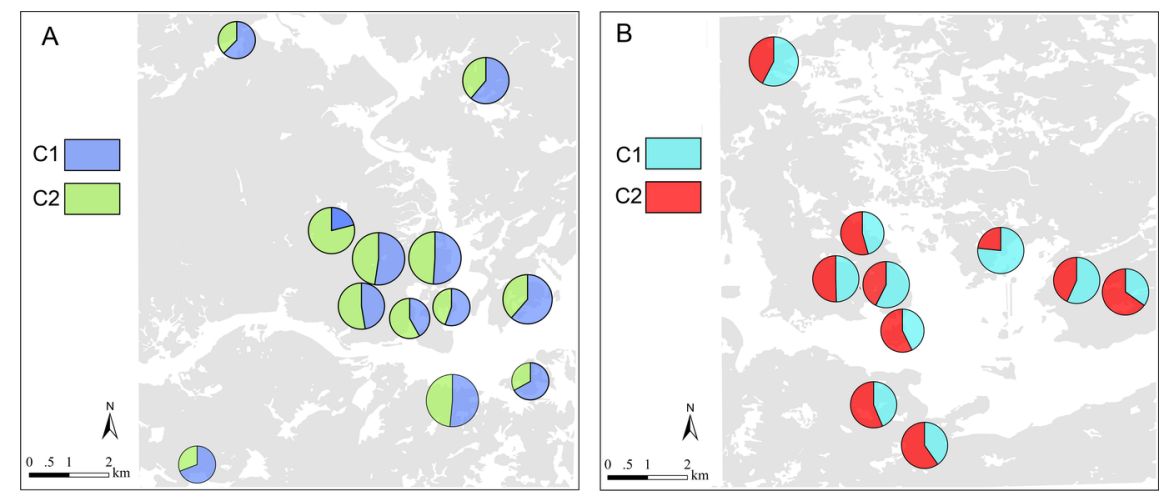

Figure 3.-Smallest cross-validation error of genetic structure detected by ADMIXTURE at a fine scale ( $\mathrm{K}=$ 2).

The two genetic clusters in Shunchang County (blue and green); (B) The two genetic clusters in Xiapu County (mint green and red). The size of each chart is proportional to the sample size. The gray area represents all forest habitats, and the white area represents other habitats. 

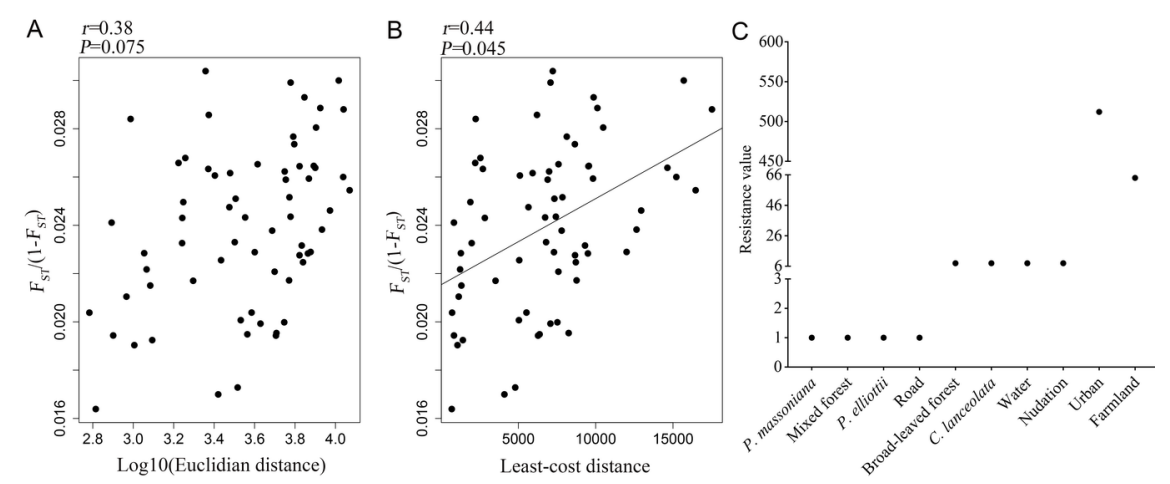

Figure 4.-Mantel correlation tests between genetic distance and (A) Euclidian or (B) least-cost distance between pairs of populations.

Least-cost distances were calculated using the opinion method resistance surface relying on the land cover surface. Only the resistance surface 1 (B) and its resistance values (C) are shown, because the other three groups of resistance values were not significant.
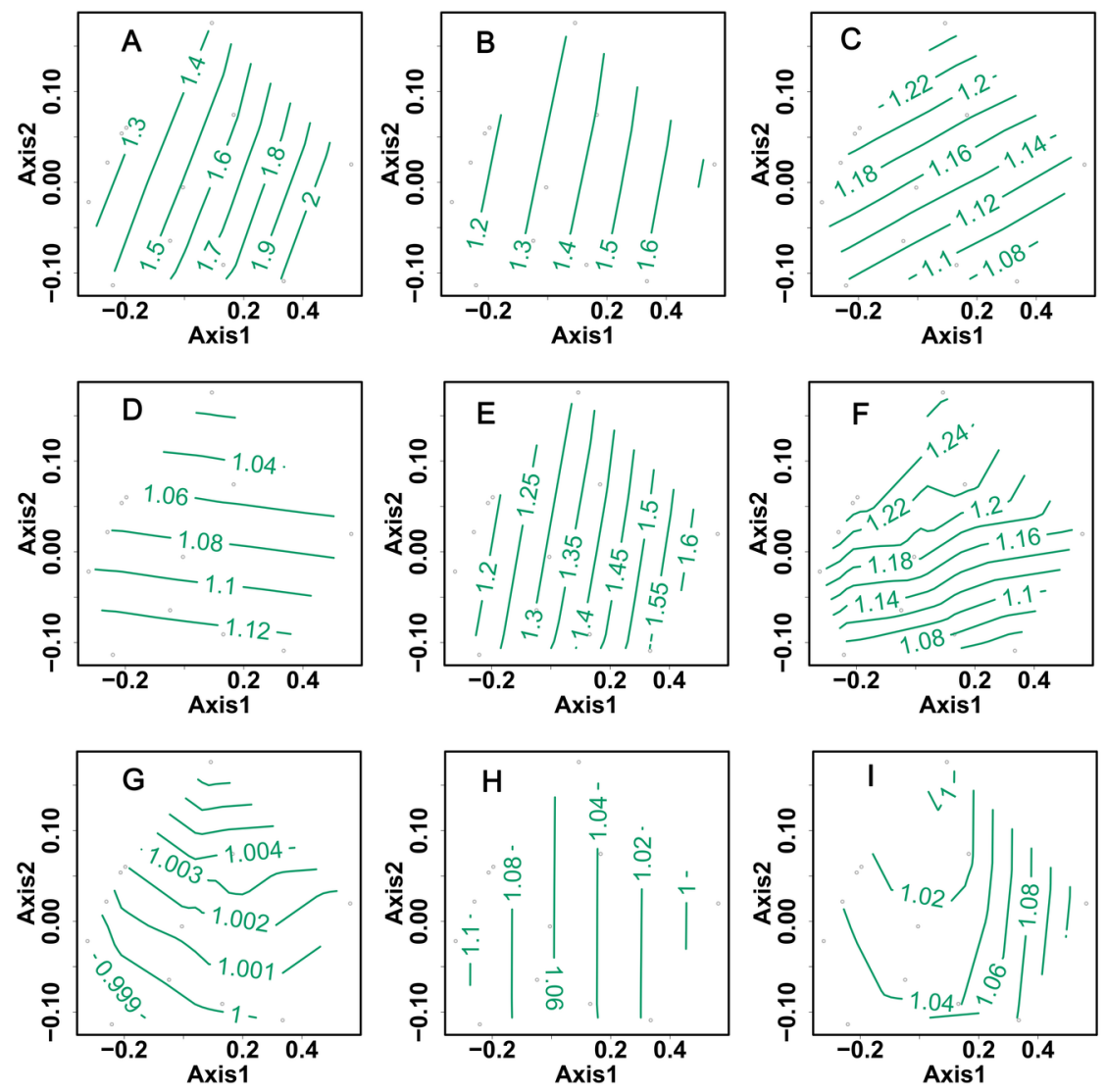

Figure 5.-Principal coordinates analysis of predictor variables and fitted as trend surfaces a posteriori by generalized additive model in Shunchang County. 
$300 \mathrm{~m}$, P. massoniana ; (B) $800 \mathrm{~m}$, P. massoniana ; (C) $800 \mathrm{~m}$, Mixed forest; (D) $800 \mathrm{~m}$, Urban; (E) 1,000 m, P. massoniana ; (F) 1,000 m, Mixed forest; (G) 1,000 m, P. elliottii ; (H) 1,000 m, Farmland; (I) 1,000 $\mathrm{m}$, Road.
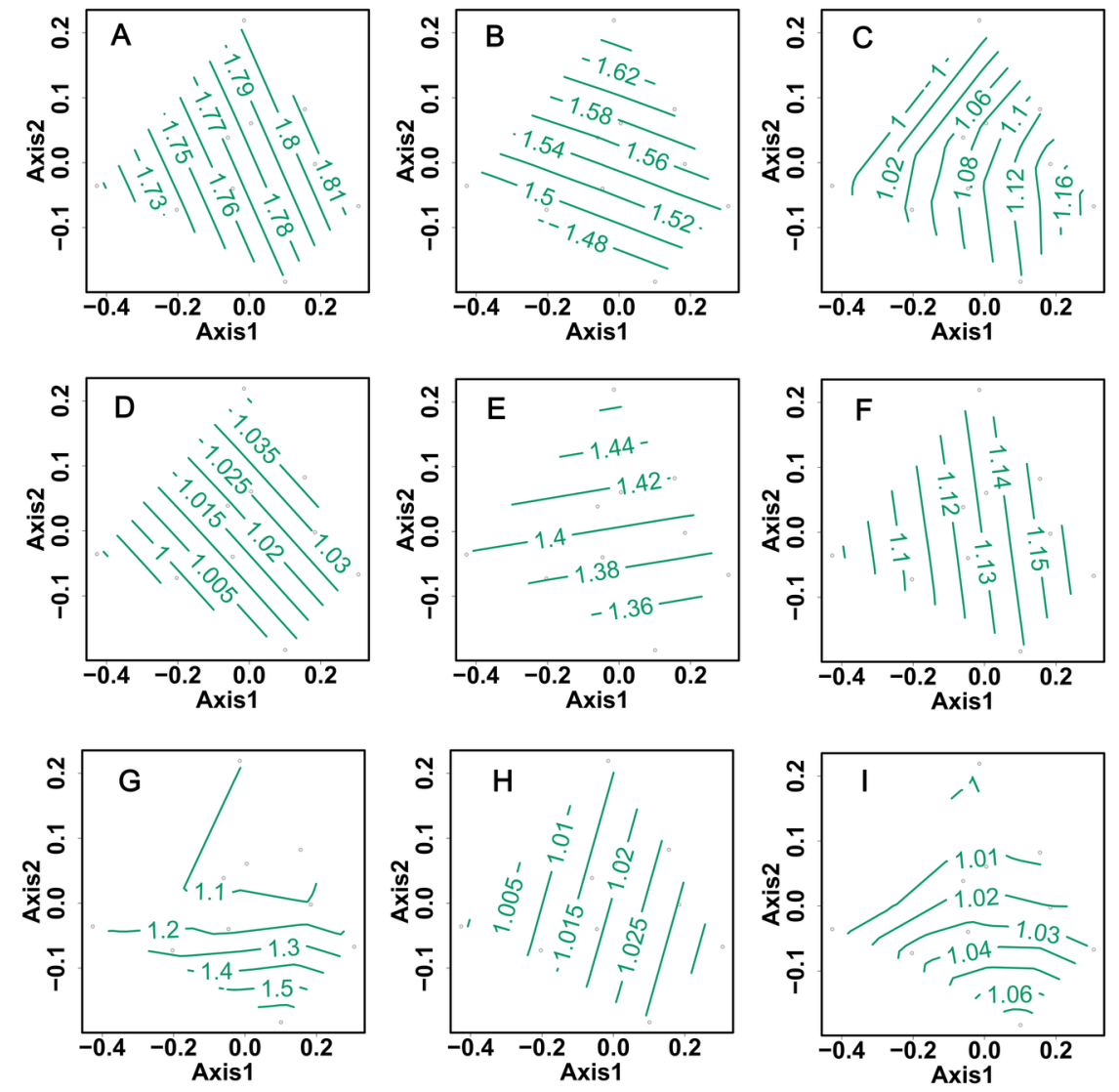

Figure 6.-Principal coordinates analysis of predictor variables and fitted as trend surfaces aposteriori by generalized additive model in Xiapu County.

(A) $300 \mathrm{~m}$, P. massoniana ; (B) $800 \mathrm{~m}$, P. massoniana ; (C) $800 \mathrm{~m}$, Mixed forest; (D) $800 \mathrm{~m}$, P. elliottii ; (E) 1,000 m,P. massoniana ; (F) 1,000 m, Mixed forest; (G) 1,000 m, Farmland; (H) 1,000 m, Road: (I) $1,000 \mathrm{~m}$, Urban. 